Arkivoc

Archive for

Organic Chemistry
The Free Internet Journal

for Organic Chemistry
Review

Arkivoc 2020, part v, 190-215

\title{
Advances in nitroarene reductive amidations
}

\author{
Paseka T Moshapo*a and Sandile B Simelane ${ }^{b}$
}

${ }^{a}$ Research Centre in Synthesis and Catalysis, Department of Chemical Sciences, University of Johannesburg, P.O. Box 524, Auckland Park 2006, South Africa

${ }^{b}$ Department of Chemistry, University of Eswatini, Private Bag 4, Kwaluseni M201, Eswatini

Email:pasekam@uj.ac.za

Received 11-12-2020

Accepted $02-02-2021$

Published on line $02-10-2021$

\section{Abstract}

The amide functional group is common in natural and synthetic products. Its prevalence in fine chemicals and pharmaceuticals has propelled a surge in the development of new synthesis procedures to access this amide bond. Nitroarenes are key building blocks in organic synthesis and are easily accessible via nitration of parent arenes. This review highlights the use of nitroarenes as alternatives to access the amide functional group. A broad range of reductive amidation reactions and their proposed mechanistic pathways are discussed.

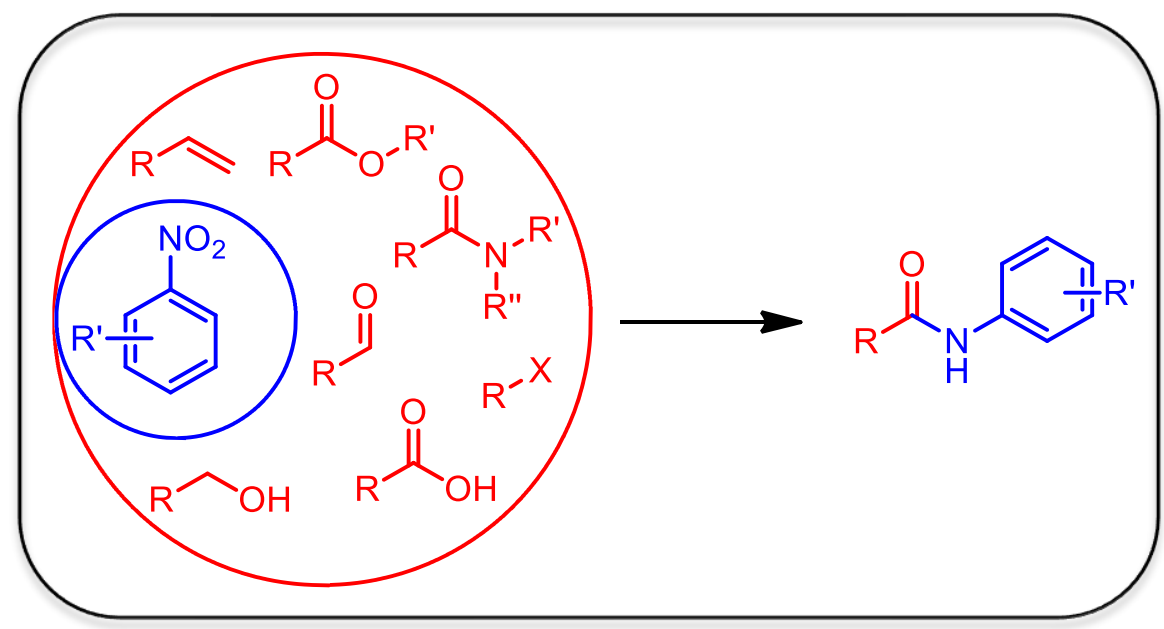

Keywords: Nitroarenes, reductive amidation, aminocarbonylation, transamidation 


\section{Table of Contents}

1. Introduction

2. Reductive Amidation of Carboxylic Acids

3. Reductive Amidation of Esters

4. Reductive Aminocarbonylations

5. Reductive Amidation of Aldehydes and Alcohols

6. Reductive Transamidations

7. Reductive Amidation of Acid Chlorides and Acid Anhydrides

8. Conclusions

\section{Introduction}

The development of new synthetic strategies to access amide bonds has been a key area in chemistry research for the past decade. These research endeavors have been propelled by the extensive feature of amides in chemical structures of natural products, ${ }^{1}$ peptides, ${ }^{2}$ polymers ${ }^{3,4}$ and small organic molecules with applications in the pharmaceutical, medical ${ }^{5,6}$ as well as agricultural industries. ${ }^{7}$ Furthermore, the identification of amide bond formation as a key green-chemistry research area by a team of pharmaceutical industry role players provided impetus for the observed surge in recent efforts aimed at developing alternative amide coupling methods. ${ }^{8,9}$ Traditionally, amide bonds are synthesized by a condensation reaction between amines and carboxylic acids at elevated reaction temperatures or by using an equivalent amount or more of carboxylic acid activators such as hexafluorophosphate azabenzotriazole tetramethyl uronium (HATU) and $N, N^{\prime}$ dicyclohexylcarbodiimide (DCC). ${ }^{10}$ The disadvantage associated with these reactions is their poor atom economy. The recently reported, and potentially life-threatening, allergic reactions linked to uronium salts raises serious health and safety concerns regarding their continued use in amidation reactions. ${ }^{11}$ Thus, catalytic amidation protocols are a more viable and attractive option. Boronic-acid derivatives are some of the most successful and efficient catalysts for direct amidation of carboxylic acids and amines at low-catalyst loading and reaction temperatures (Scheme 1). ${ }^{12,13}$ Group IV transition metals such as titanium, ${ }^{14}$ zirconium $^{15}$ and hafnium ${ }^{16}$ have also shown impressive catalytic properties.

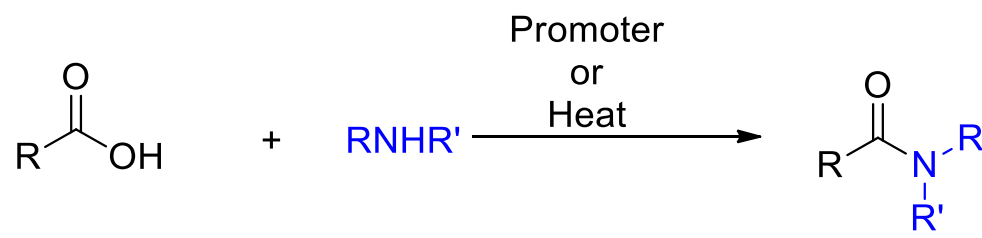

Scheme 1. Promoter or heat-driven amidation of carboxylic acids.

The use of carboxylic acid and amine surrogates such as esters, ${ }^{17}$ amides, ${ }^{18}$ aldehydes, ${ }^{19,20}$ alcohols, $^{21,22}$ and azides $^{23}$ has also gained momentum as alternative substrates for amide synthesis. These substrates present practical, and yet convenient, approaches to access amides. Most of these reactions have been well documented in recent literature reviews. ${ }^{24-33}$ Nitroarenes can also be used as amine surrogates to provide a 
step economic approach to synthesize amides as well as carbamates via reductive amidation reactions, however, their use has not been extensively highlighted. ${ }^{34,35}$ Therefore, the main objective of the current review is to bring to the spotlight the application of nitroarenes as suitable substitutes for aryl amines in amide coupling reactions. As highlighted in Scheme 2, nitroarenes can be readily reduced to their nitroso i, hydroxylamine ii and amine iii derivatives. Intermediates $\mathbf{i}$ and $\mathbf{i}$ can react to form azoxybenzene iv and azobenzene $\mathbf{v}$ which can be further reduced to amine iii. $^{36}$ All these intermediates can react to a certain extent with carbonyl sources to form amide products, and these reactions as well as their mechanisms will be covered in this review. Reductive acylation reactions with nanoparticles or nanowires are not covered in this review. ${ }^{37-39}$

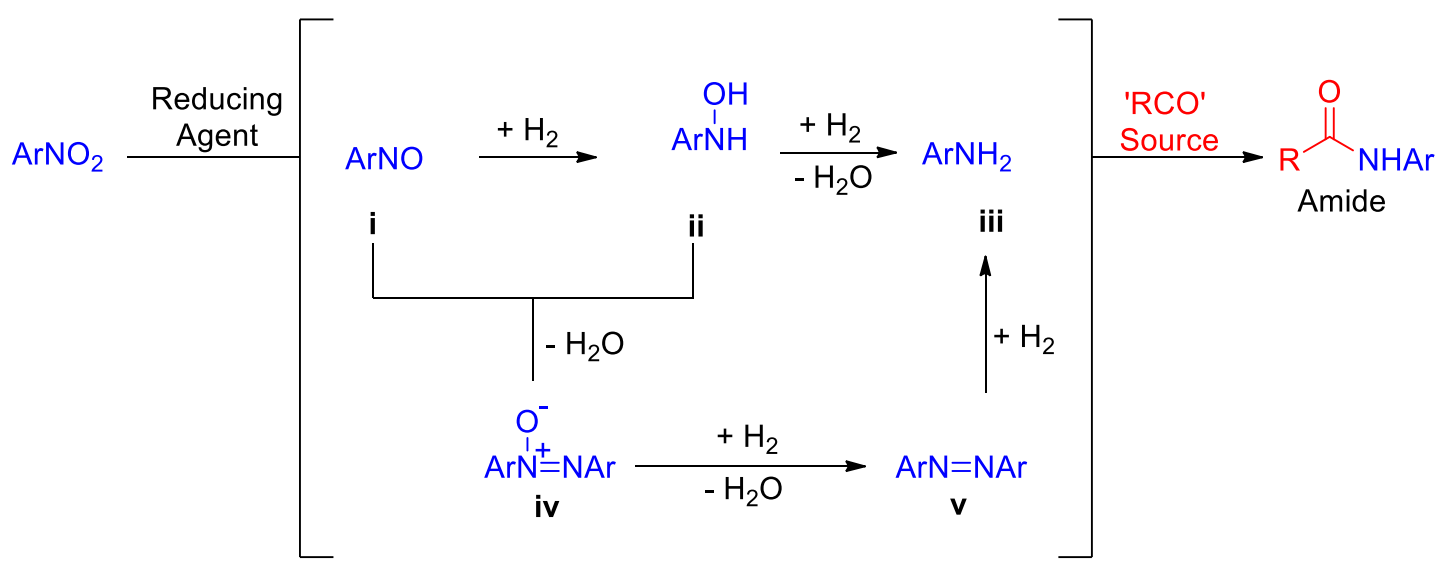

Scheme 2. Proposed general mechanism for the reduction of nitroarenes to possible reactive intermediates.

\section{Reductive Amidation of Carboxylic Acids}

Carboxylic acids are the most commonly used coupling partners with amines which are themselves derived from nitro compounds through reduction reactions. Therefore, direct reductive coupling reactions between nitroarenes and carboxylic acids are an attractive and convenient way to access amides. Reports in 1977 by Owsley and Ho represent some of the earliest reactions that shed light on reductive amidation reactions between carboxylic acids and nitroarenes. Owsley reported the use of iron powder and acetic acid to reduce nitroarenes to their acetanilide derivatives. ${ }^{40} \mathrm{Ho}$ then used molybdenum hexacarbonyl $\left(\mathrm{Mo}(\mathrm{CO})_{6}\right)$ as a reducing agent in the presence of acetic acid to afford the desired acetanilide products in moderate yields. ${ }^{41}$ In 1984, Watanabe and co-workers reported a platinum (Pt) and tin ( $\mathrm{Sn}$ ) catalyzed reductive amidation of nitroarenes with carboxylic acids such as succinic acid, acetic acid and propionic acid at 150 or $180{ }^{\circ} \mathrm{C}$ under 60 atm carbon monoxide. ${ }^{42}$ Interestingly, and as shown in Scheme 3, reactions were successful with both nitroarenes as well as nitroalkanes; however, lower product yields were obtained for the later substrates.

Proposed reaction-mechanism studies suggest a Pt-catalyzed carbon monoxide deoxygenation of the nitro functional group to form a nitrene intermediate. Pt and Sn then catalyze a CO insertion to afford the isocyanate intermediate, which then reacts with carboxylic acid to afford the amide and $\mathrm{CO}_{2}$ byproduct. Kim and co-workers later explored Owsley's iron-promoted reductive-amidation reactions, and investigated the reactivity of more carboxylic-acid substrates such as formic acid, propionic acid, butyric acid, trifluoroacetic acid, and chloroacetic acid with various nitroarenes. ${ }^{43}$ Their reactions also required more than three mol equivalences of Fe as well as reflux temperatures as reported by Owsley, and products were obtained in good to excellent yields. Kumar and co-workers recently demonstrated a direct reductive amidation of nitroarenes with carboxylic acids using 
cobalt(II) phthalocyanine catalyst and polymethylhydrosiloxane as a reducing agent. ${ }^{44}$ Their methodology was compatible with a variety of substituted nitroarenes affording products in good to excellent yields. Unfortunately, the substrate scope with carboxylic acids (just like in the case of Owsley and Ho) was limited, as reaction yields were poor with solid or aromatic carboxylic acid substrates.
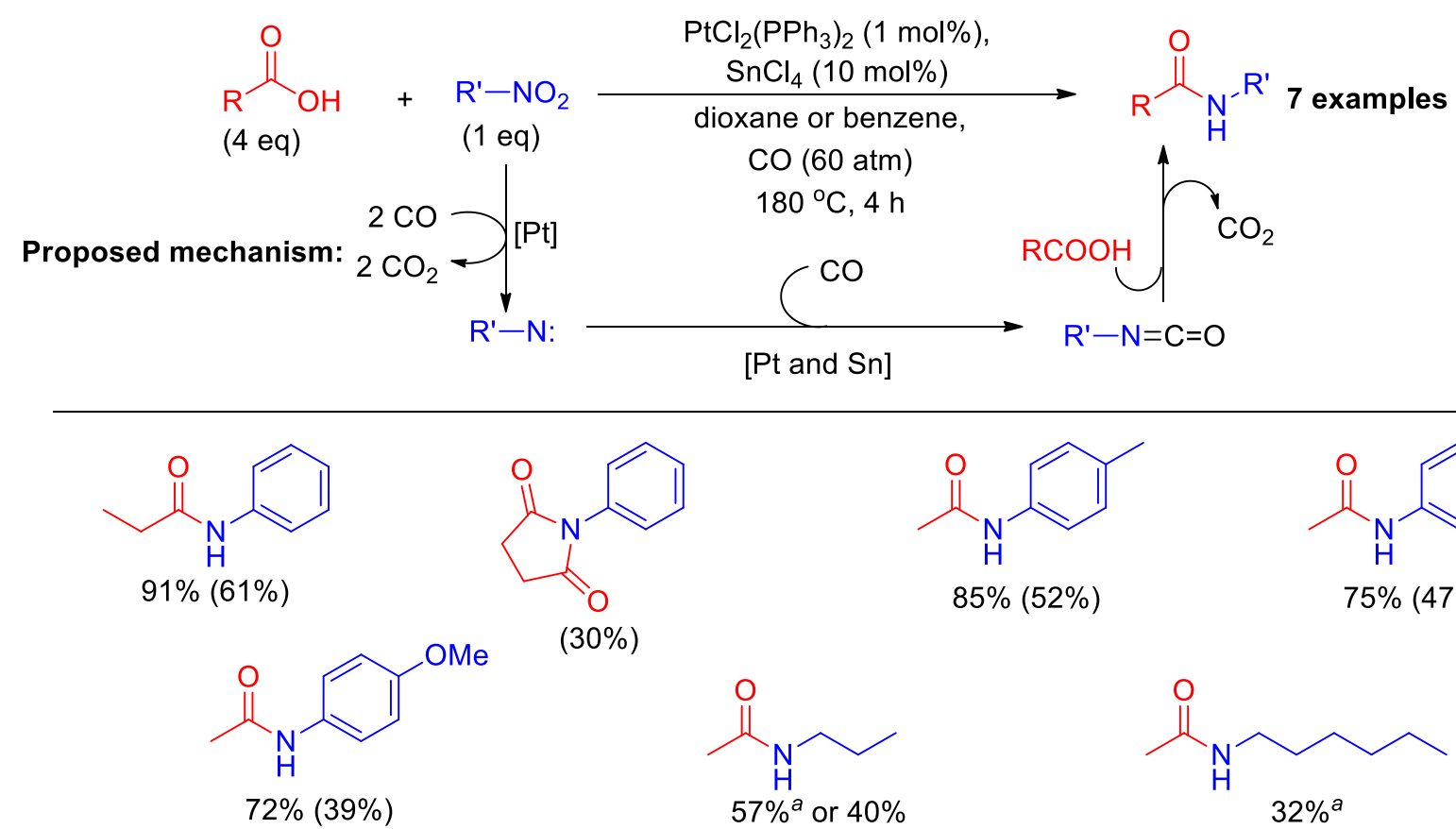

Yields determined by GC whilst isolated yields are in parentheses. ${ }^{a}$ Reactions conducted at $150{ }^{\circ} \mathrm{C}$.

Scheme 3. Platinum and tin co-catalyzed reductive amidations.

In 2006, Xu and co-workers reported a red-phosphorus-mediated and iodine- or iodide-catalyzed reductive acylation of nitroarenes. ${ }^{45}$ Excellent conversions and selectivity towards amide products were obtained with alkyl carboxylic acids whilst aryl carboxylic acids had a lower selectivity. In addition to iodine, iodide sources such as sodium iodide, potassium iodide and potassium triiodide were found to be effective catalysts, suggesting an $\mathrm{I}^{-} / \mathrm{I}^{0}$ redox cycle catalytic system. As shown in the proposed reaction mechanism in Scheme 4 , phosphorus is oxidized to phosphorus $(\mathrm{V})$ and iodine is reduced to $\mathrm{I}^{-}$which in turn reduces nitroarenes to their amine derivatives. Amidation is then promoted by the phosphorus pentaiodide intermediate.

Following earlier work on direct amidation of carboxylic acids and amines by Lakshman and co-workers, ${ }^{46}$ $\mathrm{Ma}$ and co-workers reported a modified two-step triphenylphosphine and iodine promoted reductive amidation of nitroarenes with carboxylic acids using manganese (Mn) and trimethylsilyl chloride (TMSCl) as reducing agents. ${ }^{47}$ As highlighted in Scheme 5, a broad variety of amides were synthesized from a diverse range of functionalized alkyl, (hetero)aromatic $\alpha, 6$-unsaturated carboxylic acids, and nitroarenes. Amide containing drug molecules such as mepronil, human 116-HSD1 enzyme inhibitor as well as a benzoxazole antibacterial agent were successfully synthesized to demonstrate the applicability of their protocol. Furthermore, several agrochemicals, and drug molecules possessing carboxylic acids such as ibuprofen, MCPA, naproxen, gemfibrozil and dehydrocholic acid were converted into their amide derivatives. Attempts to perform reactions in a onestep procedure afforded lower product yields. 


$$
\text { (1 eq) }
$$<smiles>CC(=O)Nc1ccc(Cl)c(Cl)c1</smiles><smiles>CCCC(=O)Nc1ccc(Cl)c(Cl)c1</smiles>

$93 \%$<smiles>CCCCCC(=O)Nc1ccc(Cl)c(Cl)c1</smiles>

$80 \%$<smiles>O=C1CCCC(=O)N1c1ccc(Cl)c(Cl)c1</smiles><smiles>O=C(Nc1ccc(Cl)c(Cl)c1)c1ccccc1</smiles><smiles>CCC(=O)Nc1ccccc1</smiles><smiles>CCC(=O)Nc1cccc(C)c1C</smiles><smiles>CCC(=O)Nc1ccc(C(F)(F)F)cc1Cl</smiles>

Proposed mechanism:

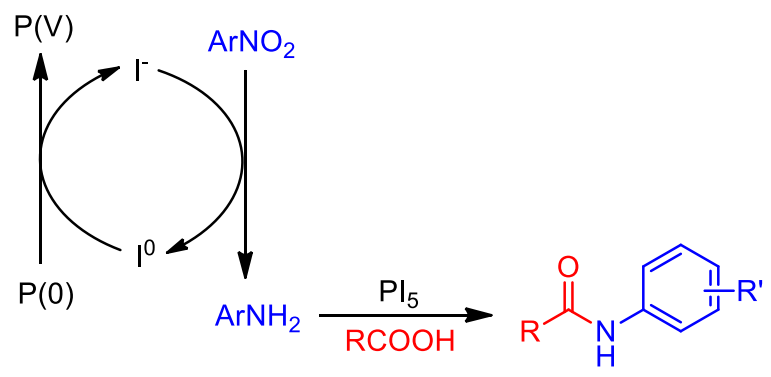

Scheme 4. Phosphorus-mediated and iodine-catalyzed reductive amidation of nitroarenes with carboxylic acids and the proposed reaction mechanism.

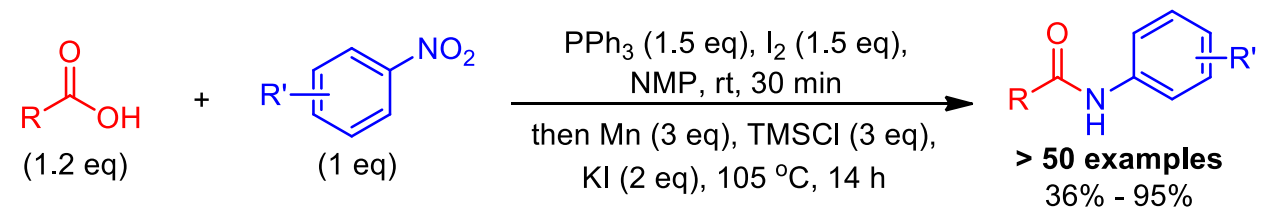<smiles>O=C(CCc1ccccc1)Nc1ccc(NC(=O)c2ccc(NC(=O)c3ccc(Cl)cc3)cc2)cc1</smiles><smiles>CN(C)c1ccc(NC(=O)/C=C/c2ccccc2)cc1</smiles><smiles></smiles><smiles>Cc1ccc(NC(=O)/C=C/c2ccccc2)cc1C#N</smiles><smiles>CC(C)Cc1ccc(C(Br)C(=O)Nc2ccc(Cl)cc2)cc1</smiles>

Ibuprofen derivative<smiles>Cc1ccccc1C(=O)Nc1cccc(OC(C)C)c1</smiles><smiles>Cc1nc2cc(NC(=O)c3cc(Cl)cc(Cl)c3)ccc2s1</smiles>

inhibitor of human $11-\beta \mathrm{HSD} 1$

Scheme 5. A representation of some amides synthesized by Ma and co-workers. 
Mechanistic studies (Scheme 6) suggest that TMSCI or TMSI (generated from halide exchange with $\mathrm{KI}$ ) acts as a deoxygenating agent and together with $\mathrm{Mn}$, reduce nitroarenes to the nitrosoarene derivative $\mathbf{i}$. This can be further reduced to the $\mathrm{N}$-aryl hydroxylamine derivative ii. Both intermediates $\mathbf{i}$ and ii can react with the acyloxyphosphonium salt iii, acyl chloride iv or iodide derivatives $\mathbf{v}$ (obtained from $\mathrm{TMSCl}$ or $\mathrm{KI}$, respectively) to form a $\mathrm{N}$-(trimethylsilyl)oxy vi or $\mathrm{N}$-hydroxy amide intermediate vii. These undergo a further $\mathrm{Mn}$-mediated reduction to afford the desired amides upon acid workup.

i)
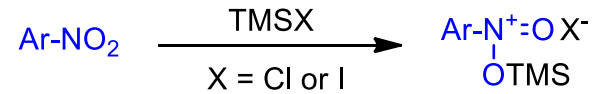
'́TMS
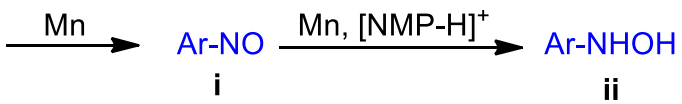

ii)

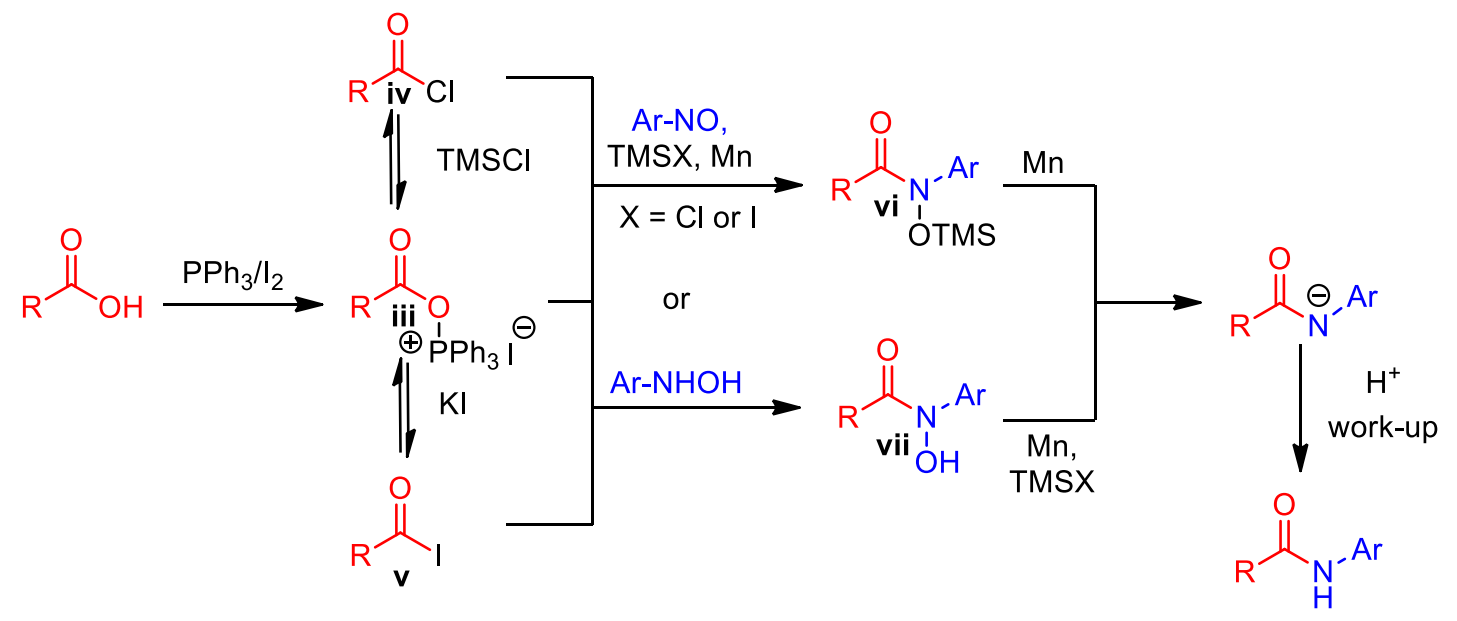

Scheme 6. Proposed $\mathrm{PPh}_{3} / \mathrm{I}_{2}, \mathrm{TMSCl}$ and $\mathrm{Mn}$-mediated reductive-amidation reaction mechanism. i) Nitroarene reduction. ii) $\mathrm{COOH}$ activation and subsequent amidation.

\section{Reductive Amidation of Esters}

Esters are present in a wide range of natural products and synthetic intermediates or products and can be easily transformed to their amide derivatives using amines in the presence of acids or bases. ${ }^{48-49}$ Reactions of esters with nitroarenes are, therefore, also desirable, as this may offer alternative protocols to access amides under relatively mild reaction conditions. Reductive amidation of esters was initially explored by Wang and co-workers who, in 2004, reported a room-temperature reductive amidation using nitroarenes and samarium diiodide $\left(\mathrm{Sml}_{2}\right) .{ }^{50}$ Electronic as well as steric effects around the nitro group did not reduce reactivity of the nitroarenes as reactions were complete within 30 minutes, forming the desired products in excellent yields. In addition, reactions were compatible with alky, aryl, and $\alpha, 6$-unsaturated esters as well as lactones (Scheme 7). In 2017, $\mathrm{Hu}$ and co-workers reported an efficient nickel ( $\mathrm{Ni}$ )-catalyzed direct amidation of esters using nitroarenes. ${ }^{51}$ Reactions were successful in the presence of $\mathrm{Ni}$ (glyme) $\mathrm{Cl}_{2}$ pre-catalyst, 1,10-phenanthroline ligand, $\mathrm{TMSCl}$ and zinc (Zn) as reducing agents as well as $N$-methyl-2-pyrrolidone (NMP) solvent (Scheme 8). Overall, the authors successfully synthesized a library of over 65 amides to establish the scope and limitations of their protocol. Highly functionalized alkyl and aromatic esters were transformed to amides using electronically diverse nitro(hetero)arenes. Amidations were successful with esters possessing $O$-alkyl or $O$-aryl groups bonded to the carbonyl carbon. 


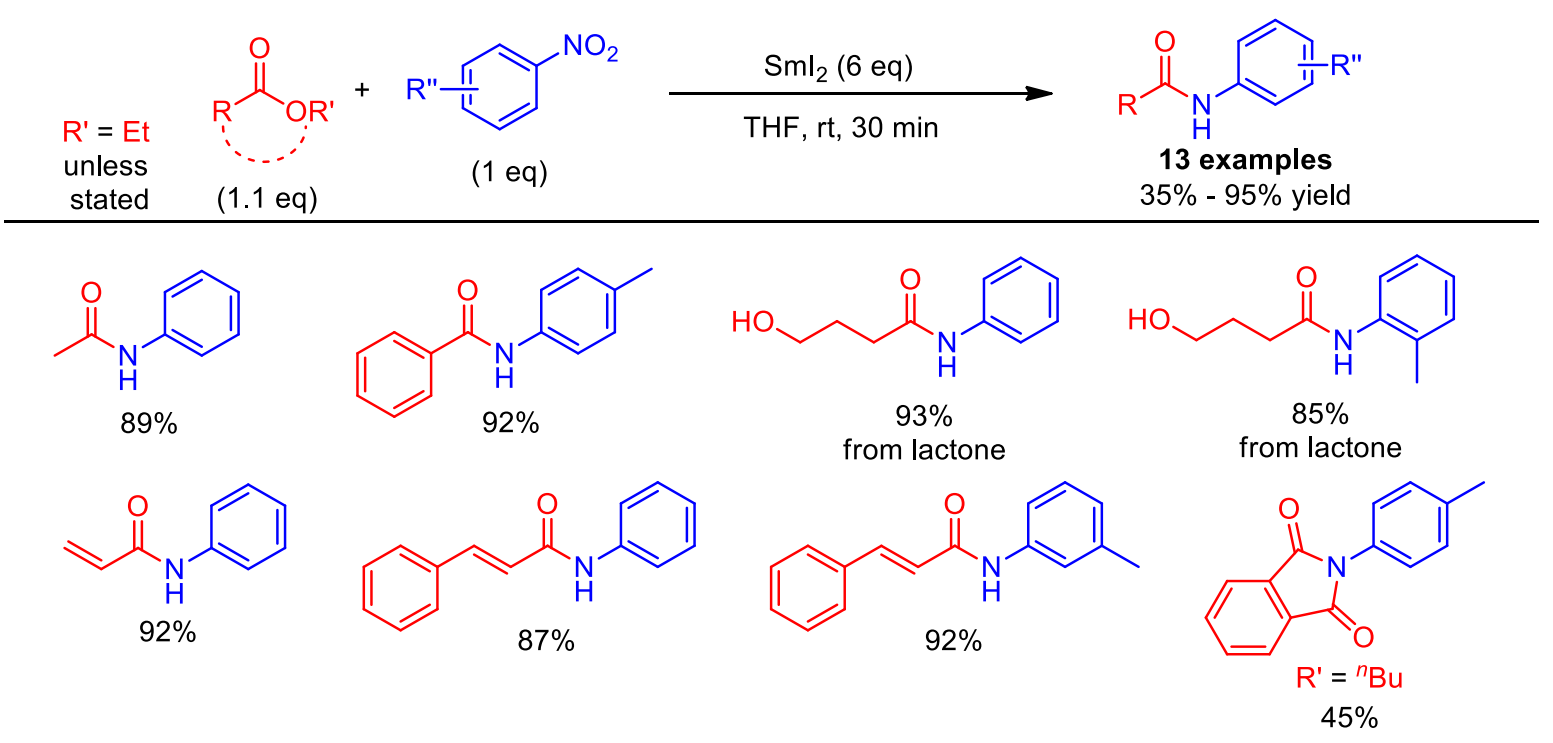

Scheme 7. Sml 2 -mediated reductive amidation of esters.

Stronger reducing agents such as Mn and TMSI as an additive as well as higher reaction temperatures, however, were required to achieve better reaction yields for sterically hindered esters. The reported protocol tolerated a broad range of base- and acid-sensitive functional groups such as carbonyls, amines, alkyl halides and alkenes. In addition, the authors demonstrated that reductive amidation with nitroarenes was efficient compared to the traditional two-step reduction of nitroarenes-to-amine derivatives followed by amidation. The reaction conditions were subsequently applied in the derivatization of valuable ester-possessing agrochemicals, and medicinal compounds such as Tazarotene and MCPA-methyl. Furthermore, application of the protocol in late-stage functionalization of nitroarenes provided alternative and more efficient routes to access amidecontaining medicinal compounds and natural products.

Although not conclusive, preliminary mechanistic studies reported by the authors propose the reaction to proceed via two possible mechanisms (Scheme 9). In the first case (A), Zn reduces $\mathrm{Ni}(\mathrm{II})$ to $\mathrm{Ni}(0)$, followed by ester insertion and subsequent reaction with azoarene (generated from $\mathrm{Zn}$ and TMSCl nitroarene reduction) to form a Ni(II) amidate ii. Two of these amidates are proposed to react with each other to form the Ni(II)-amido intermediate iii as well as azoarene. Transmetalation affords $\mathrm{Zn}$ (II)-amido intermediate iv that is protonated upon workup to afford the amide. At the same time, $\mathrm{Ni}(\mathrm{II})$ is reduced to re-enter the catalytic cycle. In another scenario (B), azoarene could react with $\mathrm{Ni}(0)$ to form the $\mathrm{Ni}(\mathrm{II})$ nitrene intermediate $\mathbf{v}$. This intermediate then reacts with an ester to form the $\mathrm{Ni}(\mathrm{II})$-amido species iii. A $\mathrm{Zn}$-amido intermediate iv is formed upon transmetalation in conjunction with a $\mathrm{Ni}$ reduction to regenerate the $\mathrm{Ni}(0)$ catalyst. Acid workup affords the desired amide. 


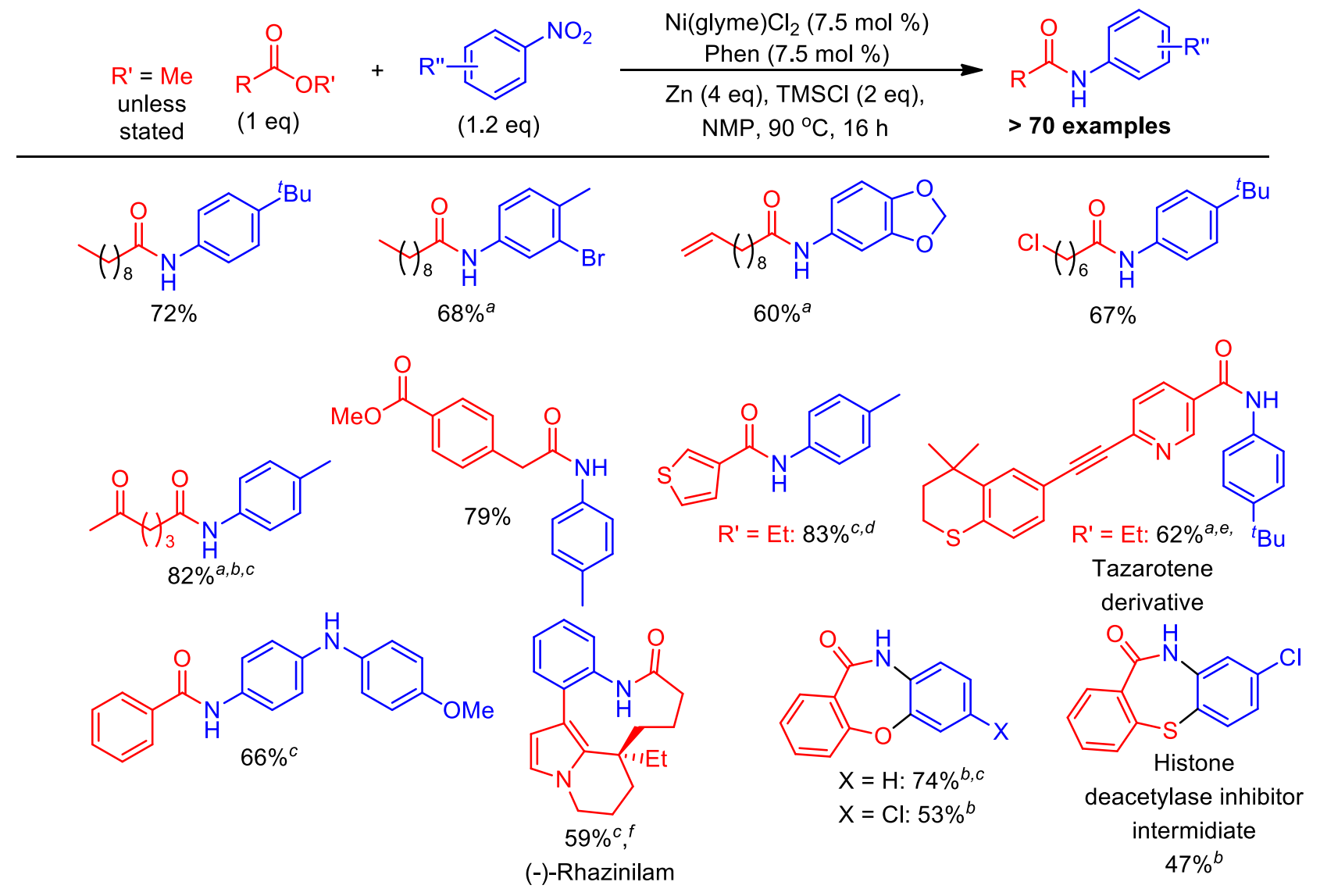

${ }^{a} \mathrm{ArNO}_{2}$ (1.5 eq); ${ }^{b} \mathrm{Ni}($ glyme $) \mathrm{Cl}_{2}$ (10 mol\%), Phen (10 mol\%); ${ }^{c} 120{ }^{\circ} \mathrm{C} ;{ }^{d} \mathrm{ArNO}_{2}$ (1.3 eq); ${ }^{e} \mathrm{Ni}(\mathrm{glyme}) \mathrm{Cl}_{2}$ (15 mol\%), Phen (15 mol\%); ${ }^{f} \mathrm{Ni}($ glyme $) \mathrm{Cl}_{2}$ (20 mol\%), Phen (20 mol\%)

Scheme 8. A representation of amides prepared by Ni-catalyzed Zn-reductive amidation.

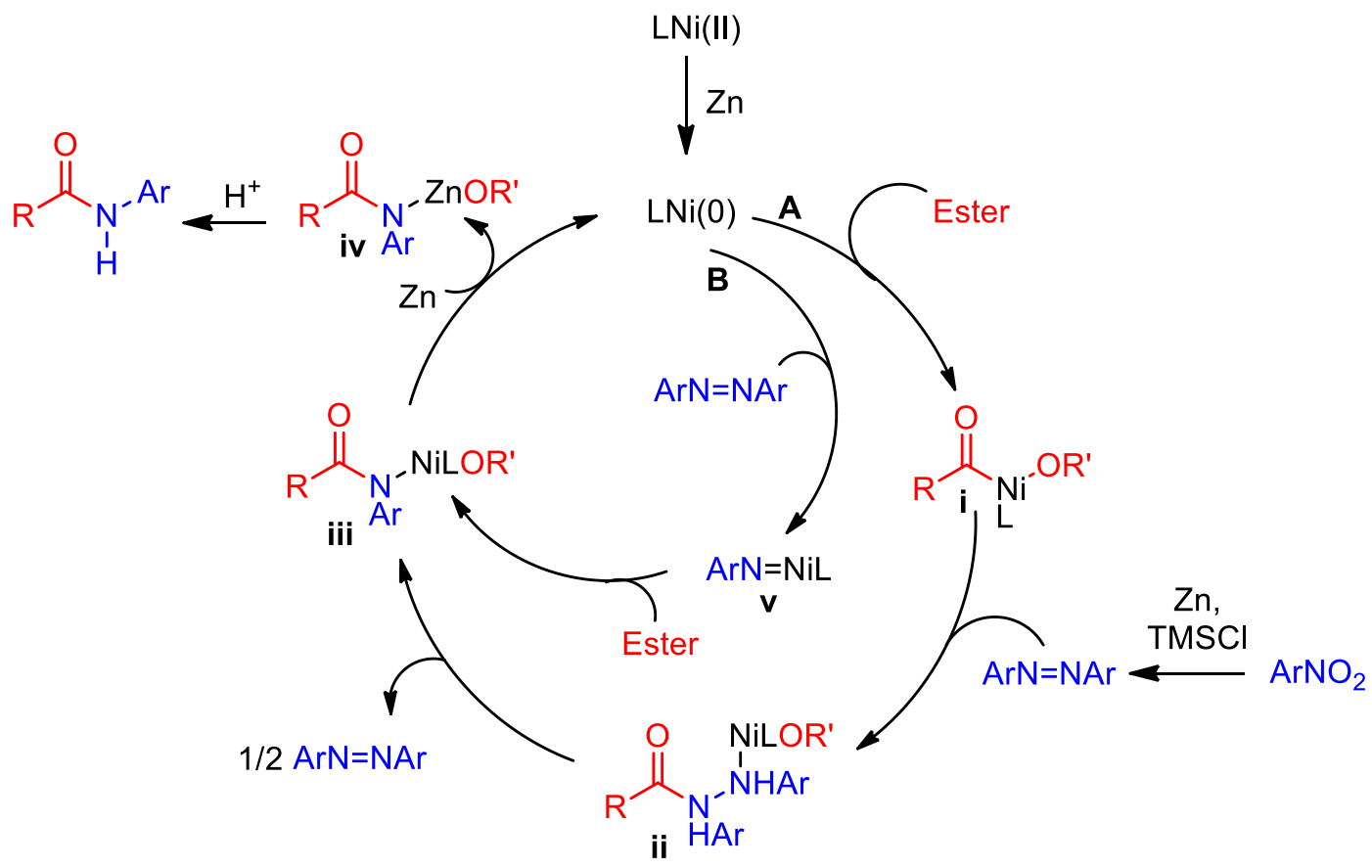

Scheme 9. Proposed Ni catalyzed and Zn mediated reductive amide coupling mechanism. 
More detailed mechanistic studies involving gas-chromatography-supported reaction monitoring, reaction kinetics, as well as Hammett plots generated from these studies, identified azoarene as the final nitrogen source from nitroarene reduction. ${ }^{52}$ In addition, DFT-computational studies proposed the Ni catalytic cycle to proceed via a complex mechanism whereby azoarene coordinates to $\mathrm{Ni}(0)$ as proposed in mechanism $\mathbf{B}$ to form the $\mathrm{Ni}(\mathrm{II})$ nitrene intermediate species vi (Scheme 10). These intermediates further react with Zn salts to form the bridged $\mathrm{Ni}_{2}$ (imide) ${ }_{2}$ intermediate vii. Monomers viii are then formed as the result of $\mathrm{N}$-Ni bond cleavage, resulting in a $\mathrm{ZnCl}_{2}$-stabilized bimetallic complex which is believed to be the species that reacts with esters to form the amides.

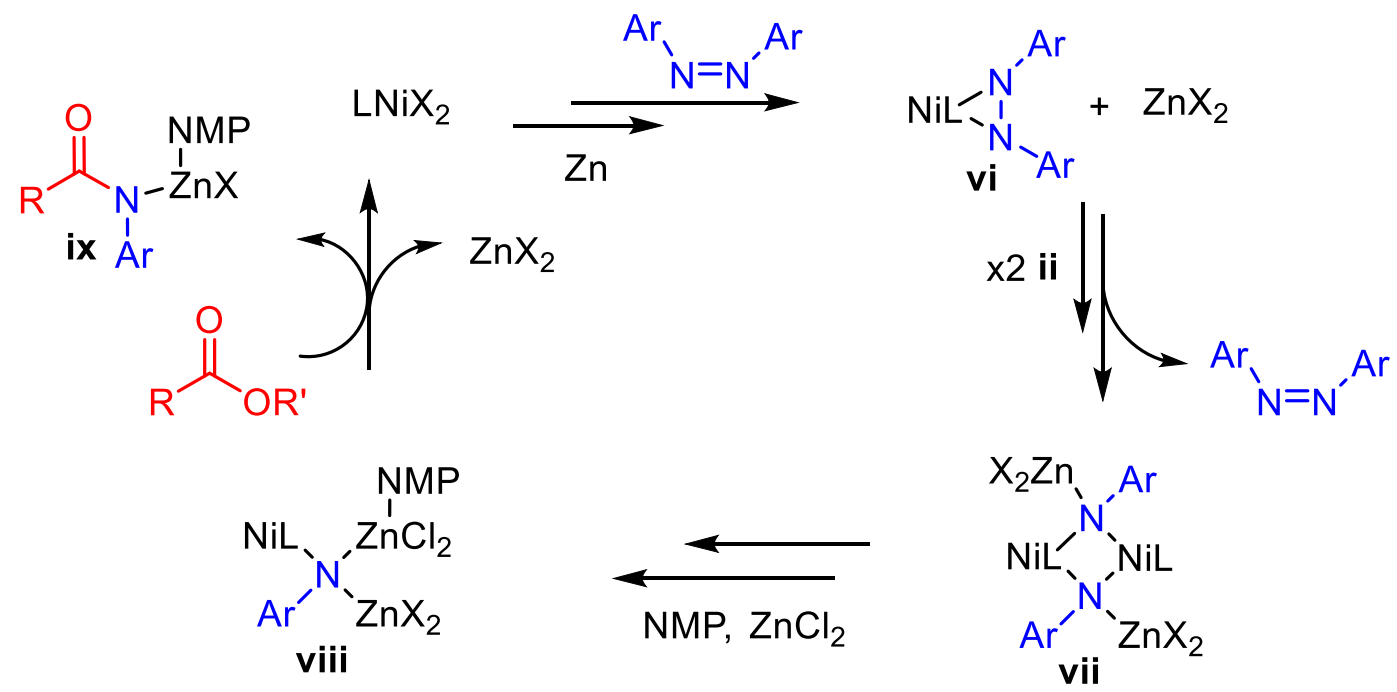

Scheme 10. Refined Ni-catalyzed and $\mathrm{Zn}$-mediated reductive-amidation mechanism. $\mathrm{X}=\mathrm{Cl}$ or OR'.

In 2019, Ma and co-workers reported an alternative reductive-ester-amidation protocol using manganese $(\mathrm{Mn})$ as both a promoter and reducing agent, thus, requiring no additional metal catalyst or ligand (Scheme 11). ${ }^{53} \mathrm{TMSCl}$ was used as a co-reducing agent whilst the use of TMSI did not improve reaction yields. No product was observed when TMSOTf was used as an additive. Amide products were successfully obtained in good-toexcellent yields from the coupling of a broad substrate scope of esters and nitroarenes. The reaction conditions were compatible with substituted alkyl and (hetero)aromatic esters with a diverse range of alkoxy, benzyloxy or aryloxy groups.

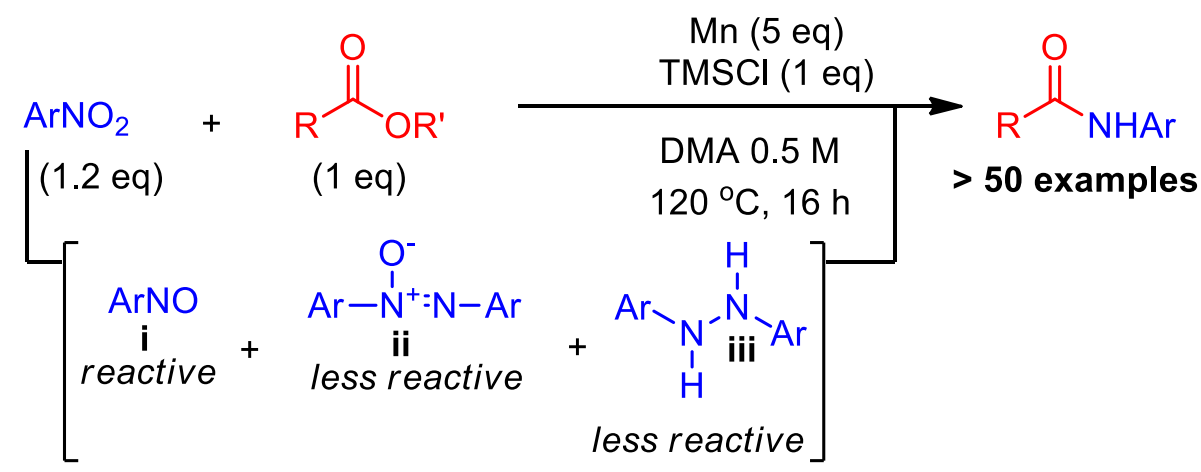

Scheme 11. Mn-mediated reductive amidation. 
The methodology was also successfully applied in the gram-scale synthesis of amide drug intermediates as well as antimicrobial agents. Preliminary reaction-mechanism studies reveal nitrosoarene $\mathbf{i}$ as a possible nitrogen source involved in the amidation step. Reactions with other possible nitroarene reduction intermediates or products such as aniline, azoarene and $\mathrm{N}$-phenylhydroxylamine did not afford any product, whilst trace amounts of product were observed for azoxyarene ii and 1,2-diarylhydrazine intermediate iii.

In 2019, Zeng and co-workers also demonstrated esters as suitable coupling partners for reductive amidation with nitroarenes, using chromium chloride $\left(\mathrm{CrCl}_{3}\right)$ as a catalyst, magnesium $(\mathrm{Mg})$ as a reducing agent and TMSCl as an additive (Scheme 12)..$^{54}$ Reactions were successful at $90{ }^{\circ} \mathrm{C}$ with aliphatic or aryl esters and substituted nitroarenes affording amides in good to excellent yields. The utility of this protocol was further demonstrated by synthesizing biologically relevant molecules as well as their derivatives. Activated esters were found to be more reactive than their inactivated counterparts, whilst electron-rich nitroarenes were more reactive than electron-poor counterparts.
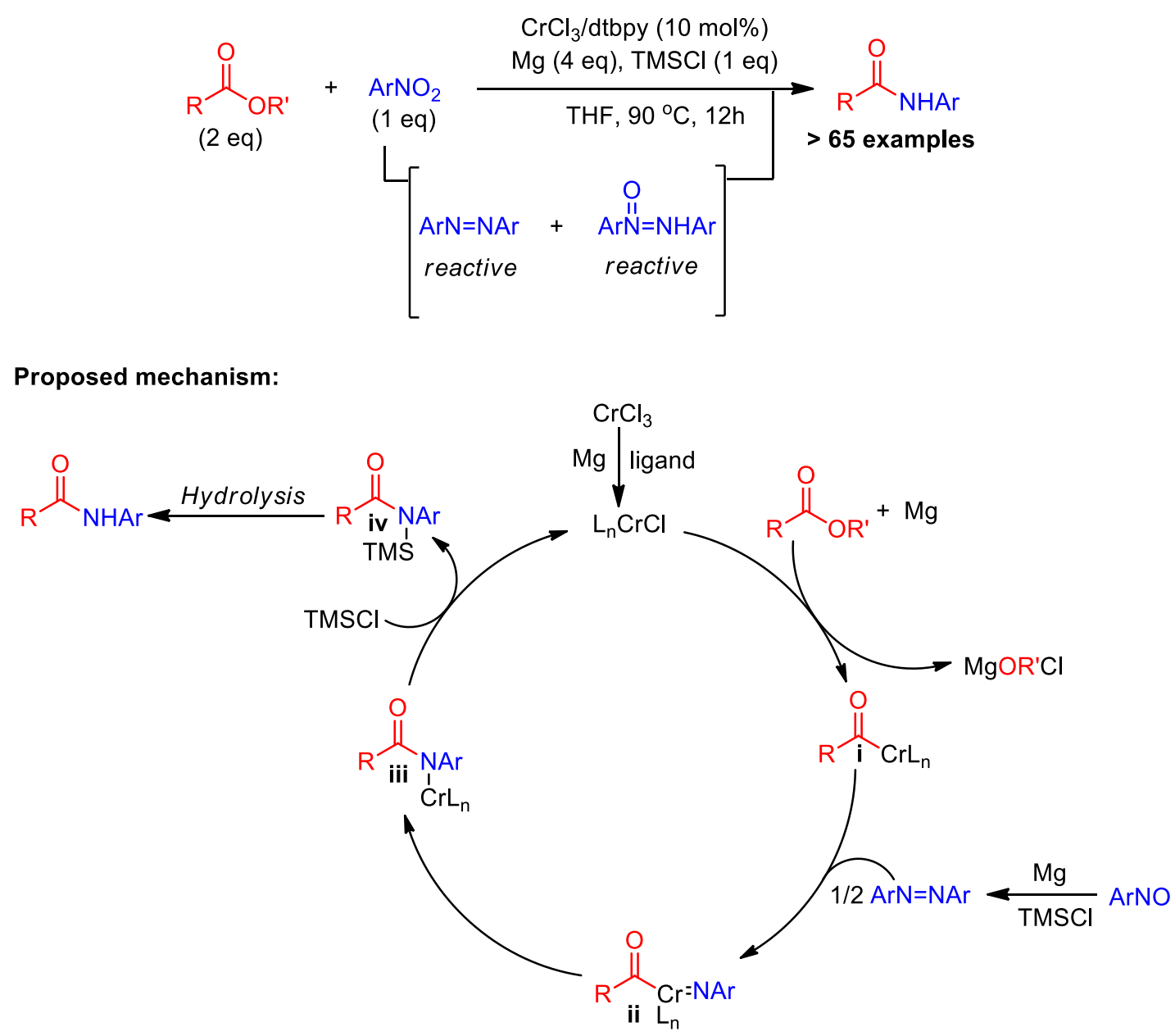

Scheme 12. Reaction scheme and mechanism of Cr-catalyzed and Mg-mediated reductive amidation of esters.

Mechanistic studies suggest a Mg-mediated reduction of $\mathrm{Cr}(\mathrm{III})$ to $\mathrm{Cr}(\mathrm{I})$. This is followed by $\mathrm{O}$-acyl bond activation to form (acyl)CrLn intermediate $\mathbf{i}$ which reacts with azoarene to form imido $\mathrm{Cr}$ intermediate ii. Insertion and amide bond formation affords intermediate iii. TMSCl promotes the formation of $N$-TMS amide iv and regeneration of $\mathrm{Cr}(\mathrm{I})$ catalyst. Hydrolysis during work-up affords the desired amide product. 


\section{Reductive Aminocarbonylations}

Aminocarbonylation reactions provide an alternative method to access amides from alkenes, alkenyl and aryl halides. In 2013, Beller and co-workers reported a Pd-catalyzed aminocarbonylation of olefins using amines or nitroarenes (Scheme 13). ${ }^{55}$ Syngas $\left(\mathrm{CO} / \mathrm{H}_{2}\right)$ was used to introduce the carbonyl functionality as well as nitroarene reduction, whilst $p$-toluene sulfonic acid $\left(p\right.$-TsOH) was used as an additive at $100{ }^{\circ} \mathrm{C}$. Although the substrate scope was limited for nitroarene reactions, aliphatic alkene substrates and nitroarenes with reducible functional groups such as ketones and nitriles were tolerated.

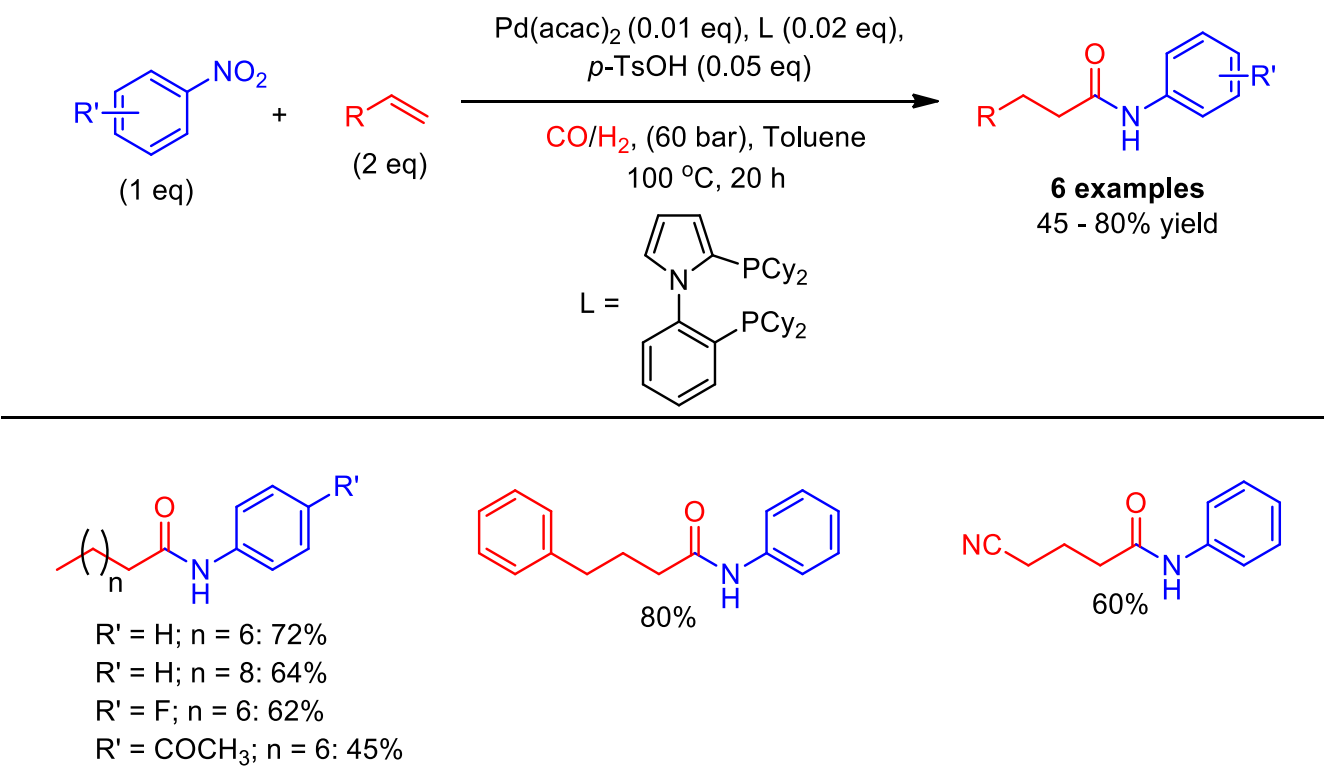

Scheme 13. Pd-catalyzed reductive aminocarbonylation of olefins.

In 2017, Driver and co-workers reported a Pd-catalyzed intermolecular $\mathrm{C}-\mathrm{H}$ aminocarbonylation of $\mathrm{N}$ heteroaryl bicyclic molecules using nitroarenes and $\mathrm{Mo}(\mathrm{CO})_{6}$ as nitrogen and carbonyl sources, respectively (Scheme 14). ${ }^{56}$ Reactions were conducted for 12 hours in DCE at $120^{\circ} \mathrm{C}$ and were successful with a variety of substituted 2-aryl pyridines. Nitroarenes with electron-withdrawing groups afforded higher product yields compared to those possessing electron-donating groups. In addition, increasing steric functionalities around the nitro group hindered the reaction. Remarkably, heteroarenes such as thiophenes, pyrroles and indoles could also undergo $\mathrm{C}-\mathrm{H}$ activation to afford corresponding amides in acceptable yields. Furthermore, the pyridine ring could be replaced with pyrimidine or an indazole to achieve structural diversity of products.

As shown in Scheme 15, the reaction mechanism proposed a nitrogen-directed C-H activation which forms palladacycle i. This compound then reacts with $\mathrm{Mo}(\mathrm{CO})_{6}$ to form a Pd-carbonyl species, ii, which reduces nitroarene to form a nitrosoarene intermediate. Nitroarene reduction simultaneously regenerates the palladacycle $\mathbf{i}$ which can reversibly form dimer iii. Palladacycle $\mathbf{i}$ then activates the 2-aryl pyridine substrate to form complex iv. Insertion of $\mathrm{CO}$ from $\mathrm{Mo}(\mathrm{CO})_{6}$ affords the acyl palladium intermediate $\mathbf{v}$ which reacts with nitrosoarene to afford the hydroxy amide intermediate vi. Mo-promoted reduction then affords the desired amide product. 

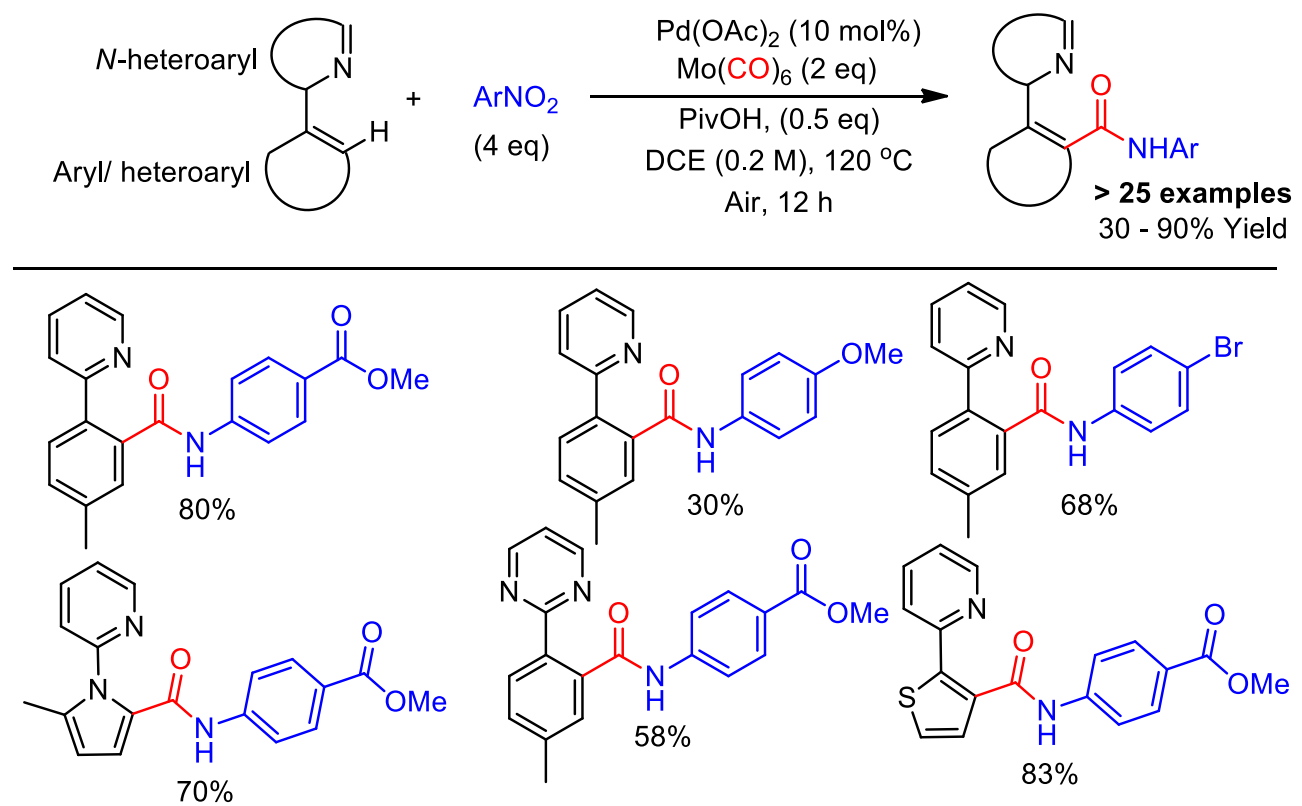<smiles>COC(=O)c1ccc(NC(=O)c2ccsc2-c2ccccn2)cc1C(=O)Nc1ccc(C(=O)Nc2ccc(C(C)(C)C)cc2)cc1</smiles>

Scheme 14. A representation of amide products obtained by Pd-catalyzed reductive $\mathrm{C}-\mathrm{H}$ aminocarbonylation.

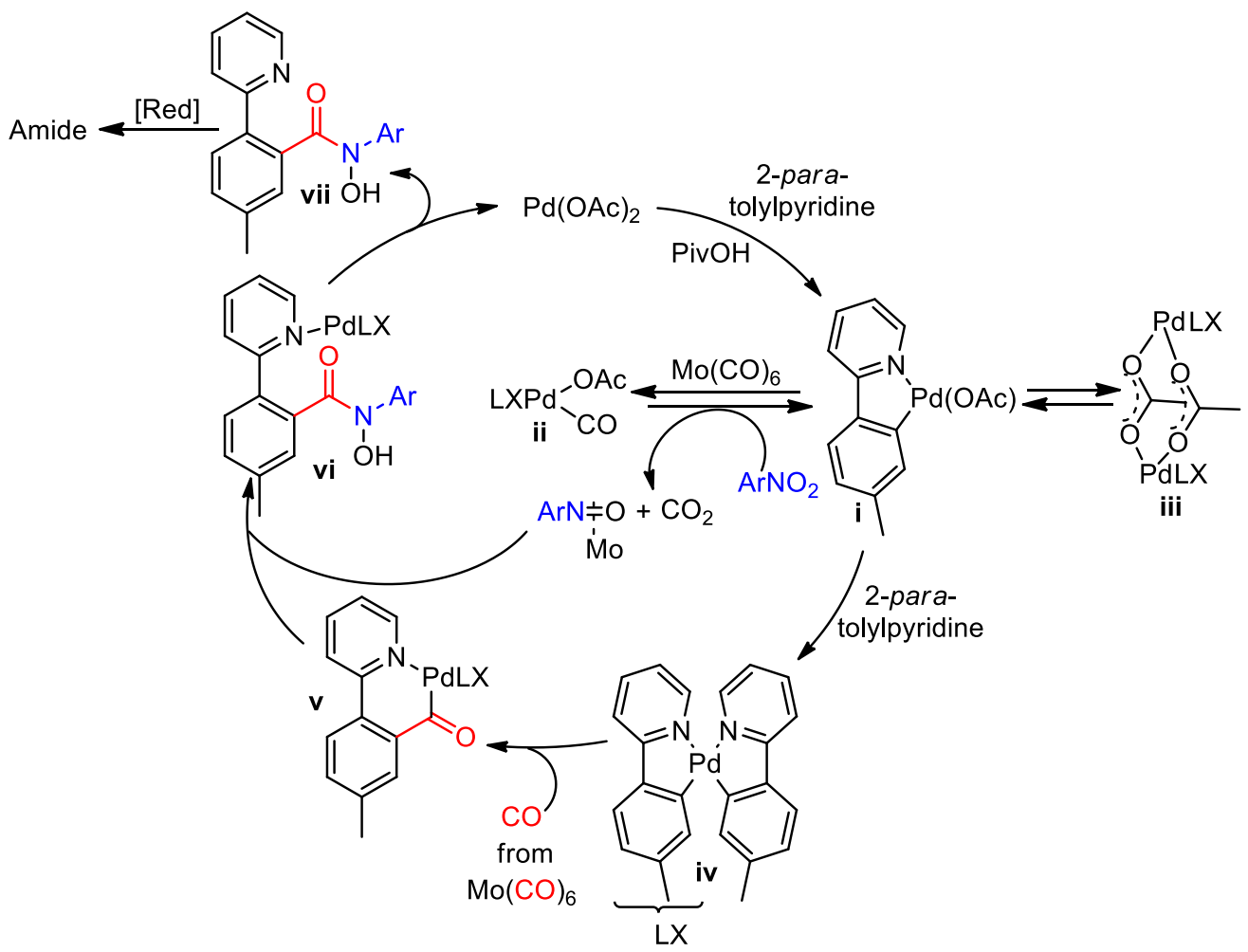

Scheme 15. Pd-catalyzed C-H aminocarbonylation.

Aminocarbonylation is the most commonly used method to construct amide bonds from aryl halides and amines, however, the use of nitroarenes as a nitrogen source in these reactions has not been widely explored. $\mathrm{Hu}$ and co-workers reported the first protocol demonstrating the use of nitroarenes in aryl halide aminocarbonylation.${ }^{57}$ In their protocol, $\mathrm{Ni}$ was used as the catalyst of choice as it is cheaper and readily 
available. Dicobalt octacarbonyl $\left(\mathrm{CO}_{2}(\mathrm{CO})_{8}\right)$ was used as a source of $\mathrm{CO}$, and $\mathrm{Zn}$ powder was used as a reducing agent in the presence of $\mathrm{TMSCl}$ (Scheme 16). Reactions were successful at $120^{\circ} \mathrm{C}$ using electronically-diverse (hetero)aryl iodides as well as bromides. Nitro(hetero)arenes possessing a variety of functional groups, such as free $\mathrm{NH}$, silyl protecting groups, esters and alkenes, were also compatible with the protocol. Steric substituents around the nitro group did not diminish product yields. Mechanistic studies proposed a $\mathrm{Ni}(\mathrm{II})$ pre-catalyst reduction by $\mathrm{Zn}$ to $\mathrm{Ni}(0)$, which then undergoes an oxidative addition to form a $\mathrm{Ni}(\mathrm{II})$-aryl halide intermediate $\mathbf{i}$. CO insertion affords acyl complex ii which then reacts with either $N$-phenyl hydroxylamine or aniline to form the amide anion iii as well as regeneration of the $\mathrm{Ni}(0)$ active catalyst. Acidic work-up affords the desired amide product.
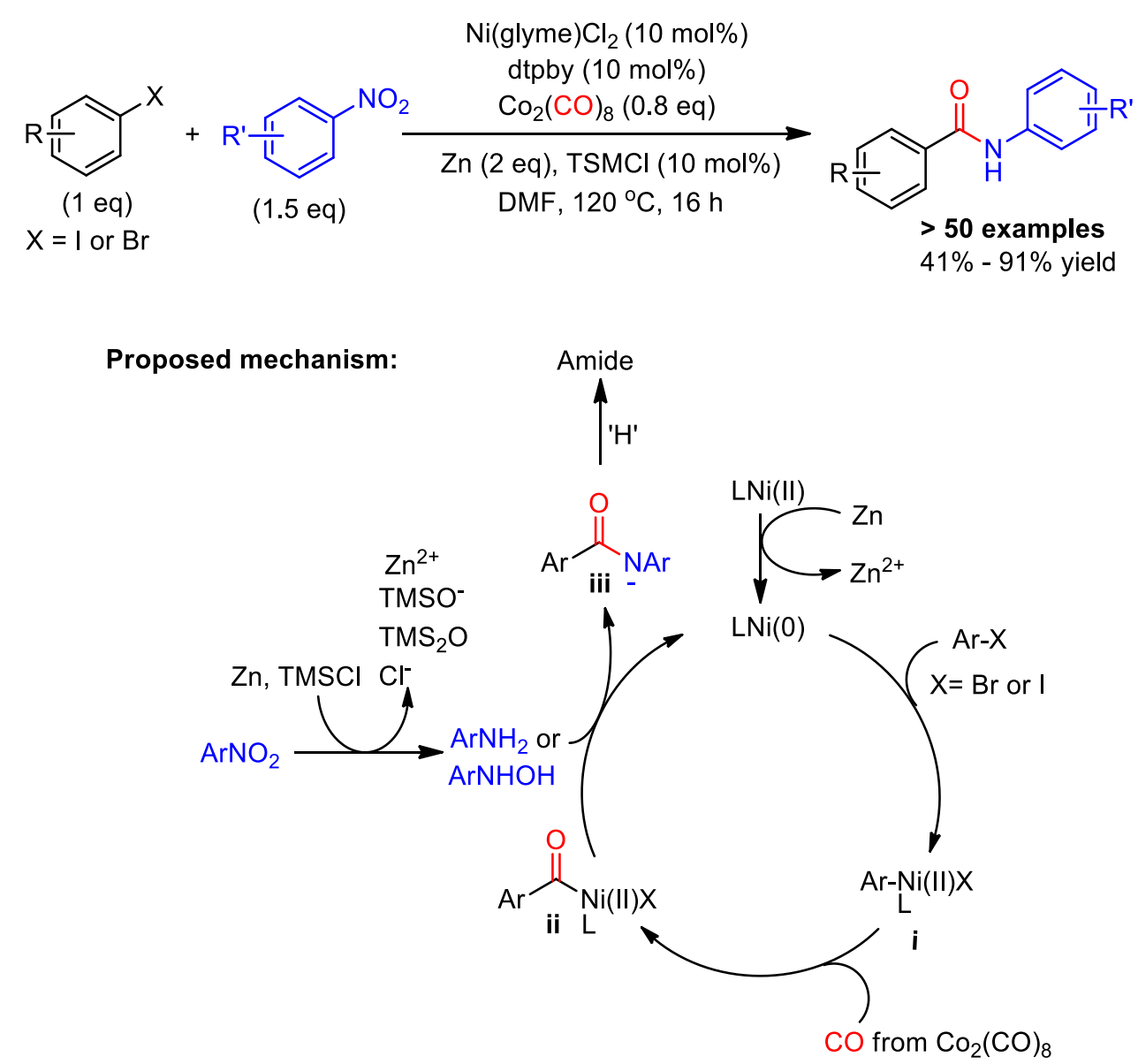

Scheme 16. Ni-catalyzed $\mathrm{Zn}$-mediated reductive aminocarbonylation of aryl halides with proposed mechanism.

In 2018, Wu and co-workers reported a Pd-catalyzed aminocarbonylation of styrenes to afford $\alpha, 6$ unsaturated amides in good stereo- and regioselectivity. ${ }^{58}$ Reactions were conducted at $130{ }^{\circ} \mathrm{C}$ for 14 hours in the presence of benzenesulfonic acid and the bidentate ligand 1,3-Bis(diphenylphosphino)propane (DPPP) (Scheme 17). Mo(CO) 6 was used as both a carbonyl source and reductant. Furthermore, nitroarene was proposed to play a dual role of oxidant and nitrogen source as reactions with aniline only produced products in the presence of nitrobenzene. Nitroarenes possessing electron-withdrawing groups afforded lower product yields, whilst electronics did not have a significant impact on the reactivities of styrenes. Aryl alkene derivatives such as trans- $\beta$-methylstyrene, $\alpha$-methylstyrene and allylbenzene did not undergo the anticipated aminocarbonylation. 

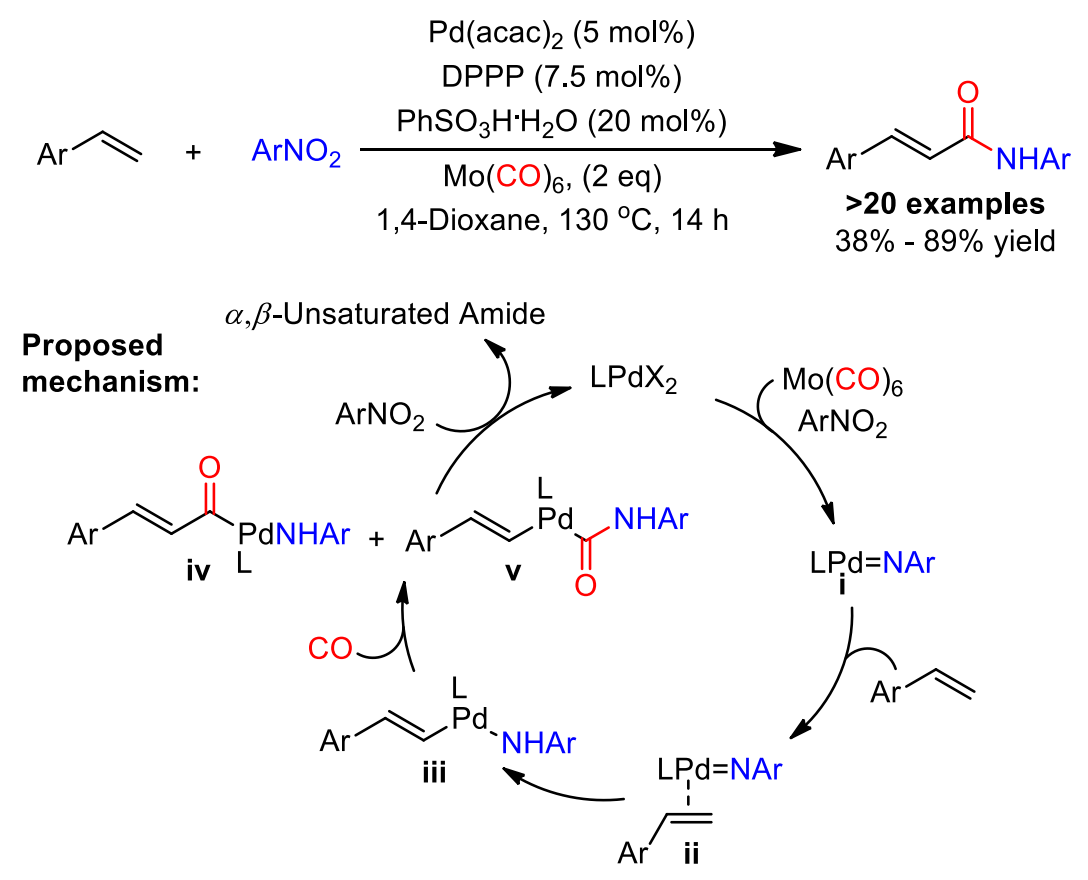

Scheme 17. Pd-catalyzed synthesis of $\alpha, \beta$-unsaturated amides and plausible reaction mechanism.

Preliminary mechanistic studies suggest a Pd reduction by Mo followed by complexation with nitroarenes to form imide species i. Coordination to styrene forms intermediate ii which is followed by a migratory insertion to give intermediate iii. CO insertion affords carbonyl-Pd intermediates iv or v. Reductive elimination affords the amide product, whilst nitroarene oxidizes $\mathrm{Pd}(0)$ to $\mathrm{Pd}(\mathrm{II})$.

In 2019, the groups of Wu and Ma reported the aminocarbonylation of boronic acids with nitroarenes using $\mathrm{Pd}$ and $\mathrm{Ni}$, respectively. ${ }^{59,60}$ In the case of $\mathrm{Pd}$-catalyzed reactions, $\mathrm{Mo}(\mathrm{CO})_{6}$ was used as a reducing agent and $\mathrm{CO}$ source. Interestingly, reactions were successful under basic conditions, and the use of acidic additives such as PTSA resulted in diminished product yields. Furthermore, reaction yields improved with the addition of $\mathrm{H}_{2} \mathrm{O}$ which is proposed to be a hydrogen source, thus, aiding in the nitroarene reduction. Ni was used as catalyst and reducing agent in aminocarbonylation reactions reported by Ma. Sodium iodide was found to improve Nicatalyst activity whilst TMSCl aided in nitroarene reduction and in their case, CO gas was used as the carbonyl source. Both protocols afforded a broad range of aryl amides in good-to-excellent yields. In the same year, Mankad and Zhao also reported a synergistic copper-catalyzed reductive aminocarbonylation of alkyl iodides with nitroarenes (Scheme 18). ${ }^{61}$ According to the authors, this represented the first, and only, example demonstrating $\mathrm{C}\left(\mathrm{sp}^{3}\right)$-hybridized electrophiles in reductive aminocarbonylation reactions. $\mathrm{N}$-heterocyclic carbene (NHC) ligands played a crucial role in preventing alkyl halide reduction. Reactions were successful with primary, secondary and tertiary halides, however, substituting iodine for bromine resulted in trace reactant conversions. Alkanes possessing aryl halides and reducible groups such as esters and cyanides afforded products in satisfactory yields. Nitrobenzene and its para-substituted derivatives afforded products in excellent yields, however, meta- or ortho-substituted derivatives afforded either low or no products. Mechanistic studies proposed a copper-mediated radical aminocarbonylation reaction. Aniline was the proposed nitrogen nucleophile as other possible nitrobenzene reduction intermediates gave low-product yields. NHC copper catalyst and $\mathrm{PhSiH}_{3}$ were also shown to play a role in reducing nitrobenzene to aniline, thus, indicating the dual role of copper in the reaction. 

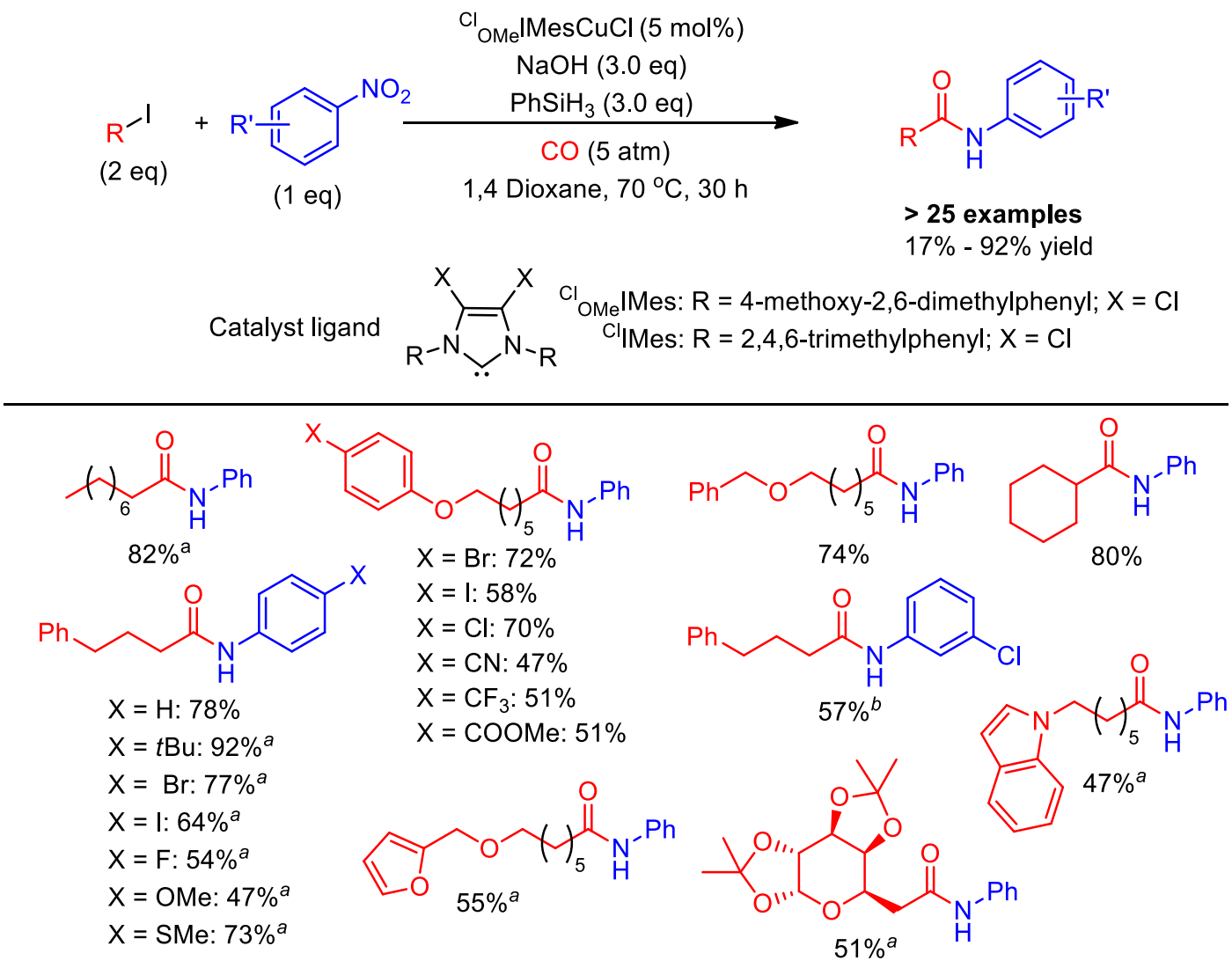

a ClIMesCuCl used instead of ${ }^{\mathrm{Cl}} \mathrm{OMelMesCuCl}^{b}$ Product isolated with $10 \%$ inseparable impurities

Scheme 18. A representation of some products obtained from Cu-catalyzed reductive-aminocarbonylation reactions.

\section{Reductive Amidation of Aldehydes and Alcohols}

Aldehydes have been widely used as suitable substrates for oxidative amide coupling with amines. ${ }^{19}$ In 2014 , Vishwakarma and co-workers reported a $\mathrm{MnO}_{2}$-catalyzed method for the synthesis of amides from aldehydes and nitroarenes (Scheme 19). ${ }^{62} \mathrm{MnO}_{2}$ is reported to play a role in the absorption and thermal deoxygenation of nitroarenes to afford the respective nitrosoarene intermediates. These intermediates then react with aldehydes to afford the observed amides. ${ }^{63}$ Reactions were performed at $60^{\circ} \mathrm{C}$ in the presence of acetic acid as an additive, and afforded the desired amides in $\mathrm{CHCl}_{3}$. The use of greener solvents such as methanol afforded lower product yields. A variety of amides were synthesized by varying substituents on aromatic aldehydes whilst ortho-halosubstituted nitroarenes afforded minor product yields. Reactions with aliphatic nitro compounds did not afford the desired products. The authors were able to obtain both amides and hydroxamic acids in a 3:7 ratio using solvent-free conditions and a base as an additive.

In 2015, Zhang and co-workers reported a green and efficient protocol for synthesis of aromatic amides from aldehydes and nitroarenes using $\mathrm{Zn}$ as a reducing agent and $\mathrm{NaClO}_{3}$ as an oxidizing additive (Scheme 20). ${ }^{64}$ Amide products were obtained at low reaction temperatures, and in relatively short reaction times. The protocol was also tolerated by a variety of functional groups such as alcohols, alkenes, halides, ester, ketones, carboxylic acids and nitro heterocycles. 


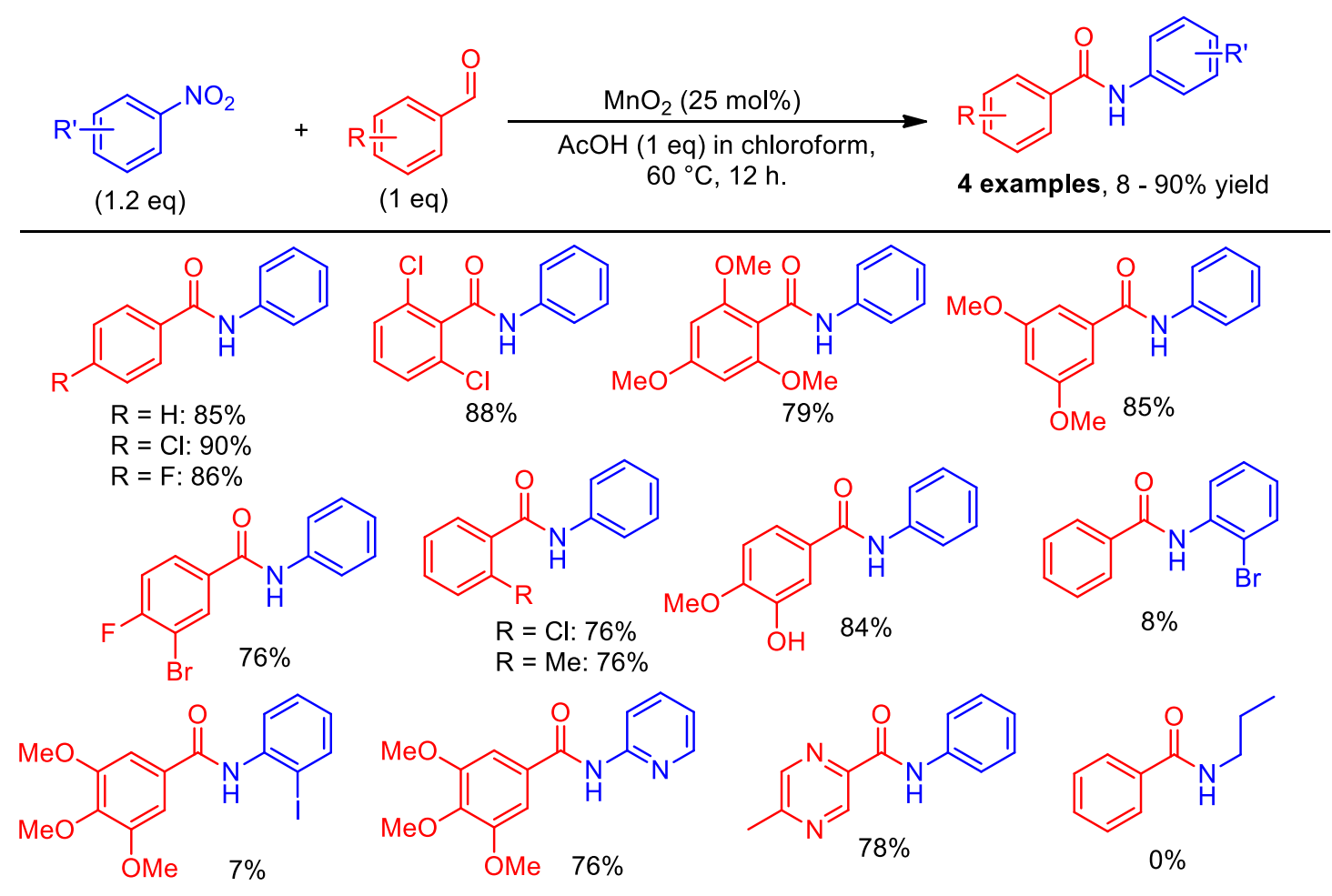

Scheme 19. $\mathrm{MnO}_{2}$-mediated amidation of nitorarenes using aldehydes.

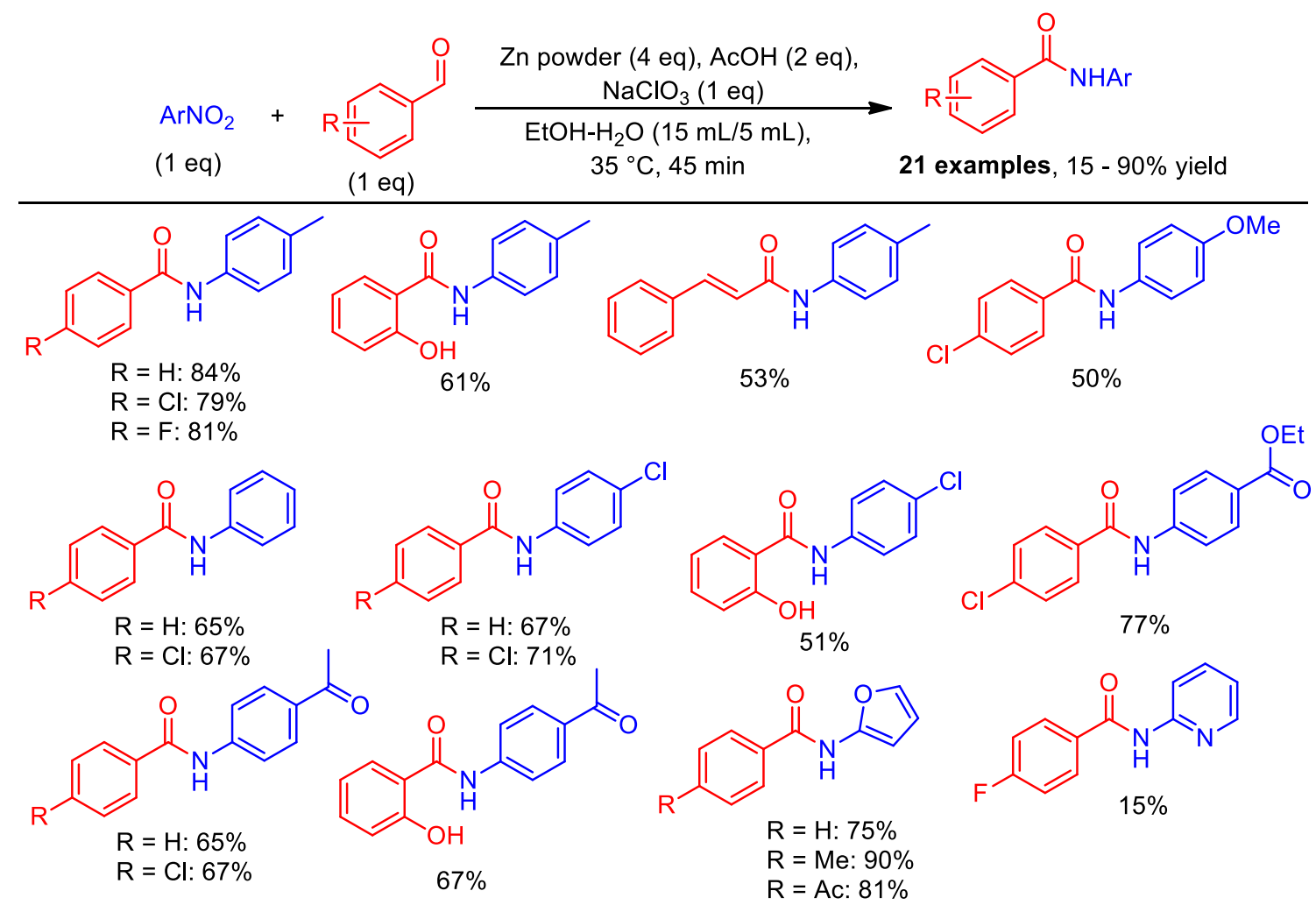

Scheme 20. A representation of amide products reported by Zhang et al. 
Alcohols can also be oxidized into their aldehyde derivatives in situ and subsequently be converted to amides. ${ }^{65,21}$ In 2012, Deng and co-workers reported a transition-metal-free alcohol oxidative amidation protocol using nitroarenes as a nitrogen source (Scheme 21). ${ }^{66}$ Chlorobenzene was the solvent of choice as it afforded the highest product yields, whilst tert-butyl peroxide (TBP) was the most effective oxidizing agent. Changing base from $\mathrm{KOH}$ resulted in diminished product yields. A broad range of benzyl alcohols and nitroarenes were reacted to afford aromatic amides in moderate-to-good yields. Electron-donating or -withdrawing groups did not reduce the reactivity of the benzyl alcohols or nitroarenes. Aliphatic alcohols and aliphatic nitro compounds did not afford the desired products. Control experiments designed to establish the reaction mechanism suggest an in situ generated aldehyde (obtained from TBP oxidation of the respective benzyl alcohol) and azoxybenzene (obtained from basic reaction conditions in the presence of phenyl chloride) as the reactive intermediates that form the observed amide products.

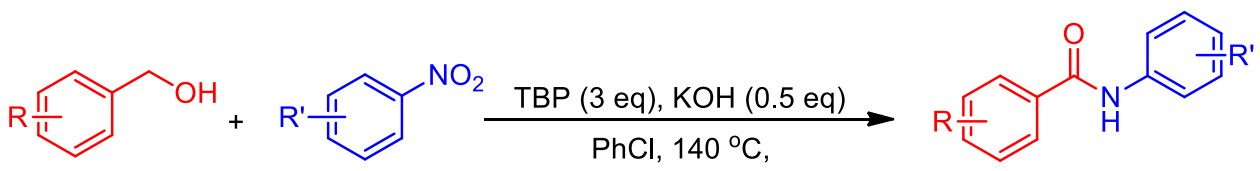

(3 eq)

(1 eq)

$24 \mathrm{~h}$, air

18 examples

$46 \%-76 \%$ yield
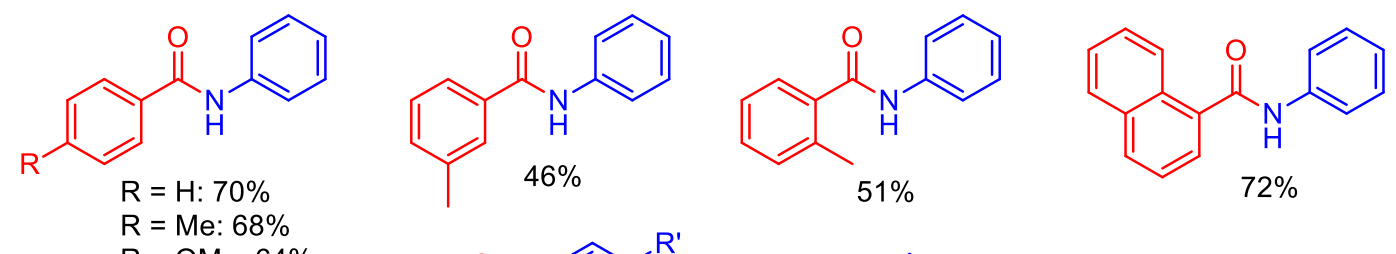

$\mathrm{R}=$ OMe: $64 \%$

$\mathrm{R}=\mathrm{F}: 72 \%$

$\mathrm{R}=\mathrm{Br}: 55 \%$

$\mathrm{R}=\mathrm{Cl}: 67 \%$<smiles>[R]c1ccc(NC(=O)c2ccccc2)cc1</smiles>

$\mathrm{R}^{\prime}=\mathrm{Me}: 66 \%$

$\mathrm{R}^{\prime}=\mathrm{OMe}: 76 \%$

$R^{\prime}=F: 51 \%$

$\mathrm{R}^{\prime}=\mathrm{Cl}: 72 \%$

$\mathrm{R}^{\prime}=\mathrm{Br}: 70 \%$<smiles>[R]c1cccc(NC(=O)c2ccccc2)c1</smiles>

$\mathrm{R}^{\prime}=\mathrm{Br}: 63 \%$

$\mathrm{R}^{\prime}=\mathrm{Cl}: 65 \%$<smiles>Cc1ccccc1NC(=O)c1ccccc1</smiles>

$51 \%$<smiles>Cc1cccc(NC(=O)c2ccccc2)c1</smiles>

$52 \%$

Scheme 21. tert-Butyl hydroperoxide (TBP)-mediated oxidative amidation of alcohols.

\section{Reductive Transamidations}

Amides form part of a wide range of natural and synthetic products, and their transformation into new amide products is attractive. These reactions may be challenging, however, due to possible competition between the reacting amine and the ensuing amine byproduct. In 2017, Hu and co-workers reported a Ni-catalyzed and $\mathrm{Zn}$ TMSI-mediated reductive transamidation of Boc-activated secondary amides with nitroarenes (Scheme 22). ${ }^{67}$ 


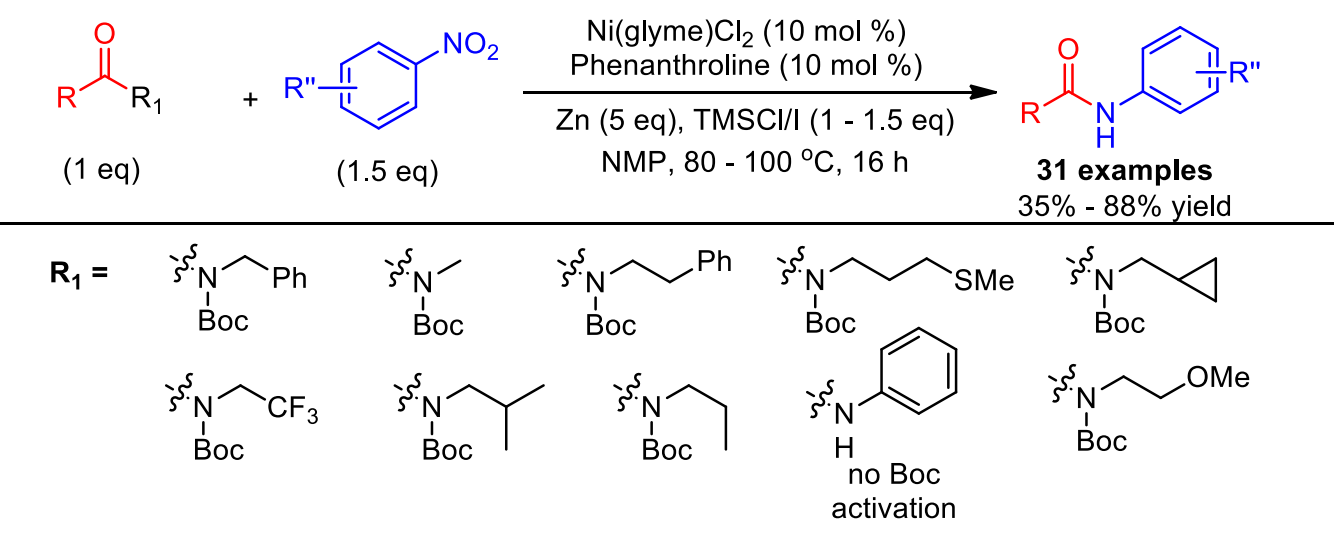

Scheme 22. Ni-catalyzed and $\mathrm{Zn}$-mediated reductive transamidation of Boc-activated amides.

The methodology was compatible with various functional groups such as alkenes, halides, ketones, sulfones as well as heteroarenes. As a result, amide products were furnished in moderate-to-excellent yields from highlyfunctionalized alkyl and aryl amides, as well as nitro(hetero)arenes. Furthermore, this protocol afforded products in higher yields when compared to $\mathrm{AlCl}_{3}$-catalyzed transamidation with aniline. An example with a Bocunprotected amide afforded the transamidation product in $49 \%$ yield suggesting applicability of the protocol with free amides. Azoarene was identified as the possible reactive intermediate formed from nitroarene reduction.

The same group of Hu later reported a manganese-facilitated reductive transamidation of the more challenging tertiary amides with nitroarenes (Scheme 23). ${ }^{68}$ The use of $\mathrm{Ni}$ catalyst was not necessary as it did not improve reaction yields significantly. The use of other metals reductants such as $\mathrm{Zn}, \mathrm{Fe}$ and $\mathrm{Cu}$ did not afford the desired amides. Reactions were successful with amides bearing $\mathrm{N}, \mathrm{N}$-dialkyl, -diaryl, or $\mathrm{N}$-alkyl- $\mathrm{N}$-aryl groups, affording a broad range of highly-factionalized amide products in good-to-excellent yields. The protocol was also applied in the trans-amidation of bioactive molecules as well as in the synthesis of drug-like molecules. Azoarene was also identified as the possible reactive intermediate.
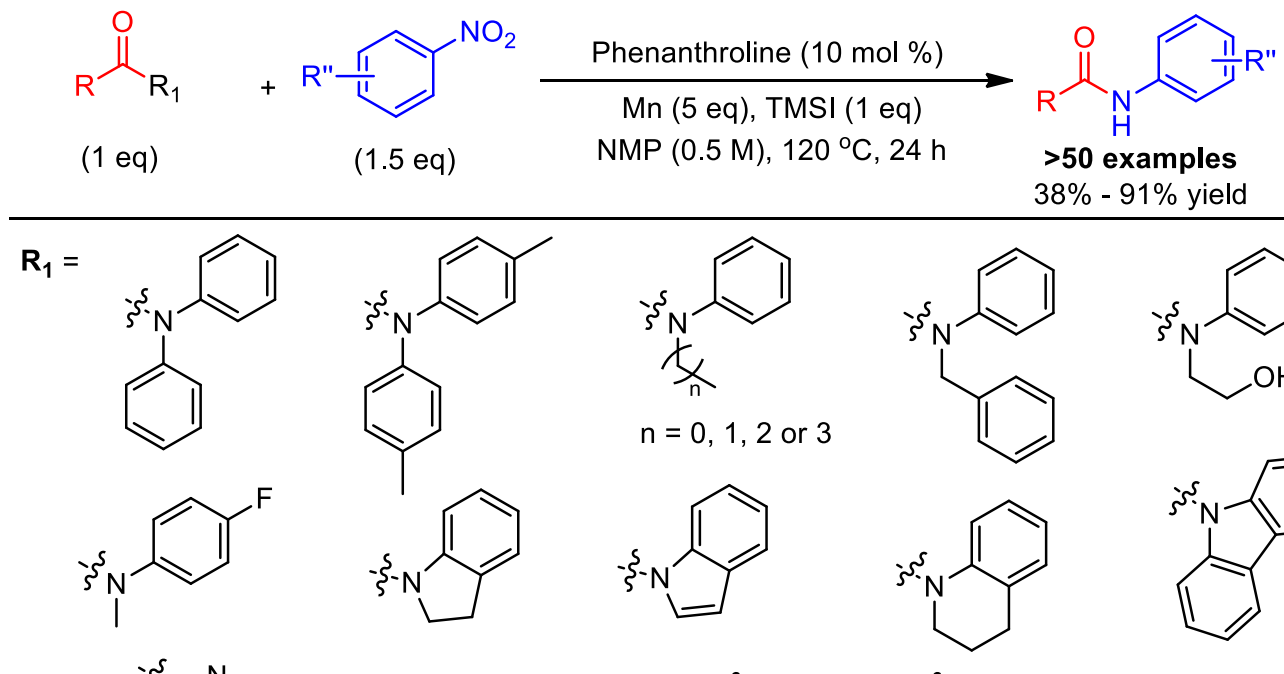

$38 \%-91 \%$ yield
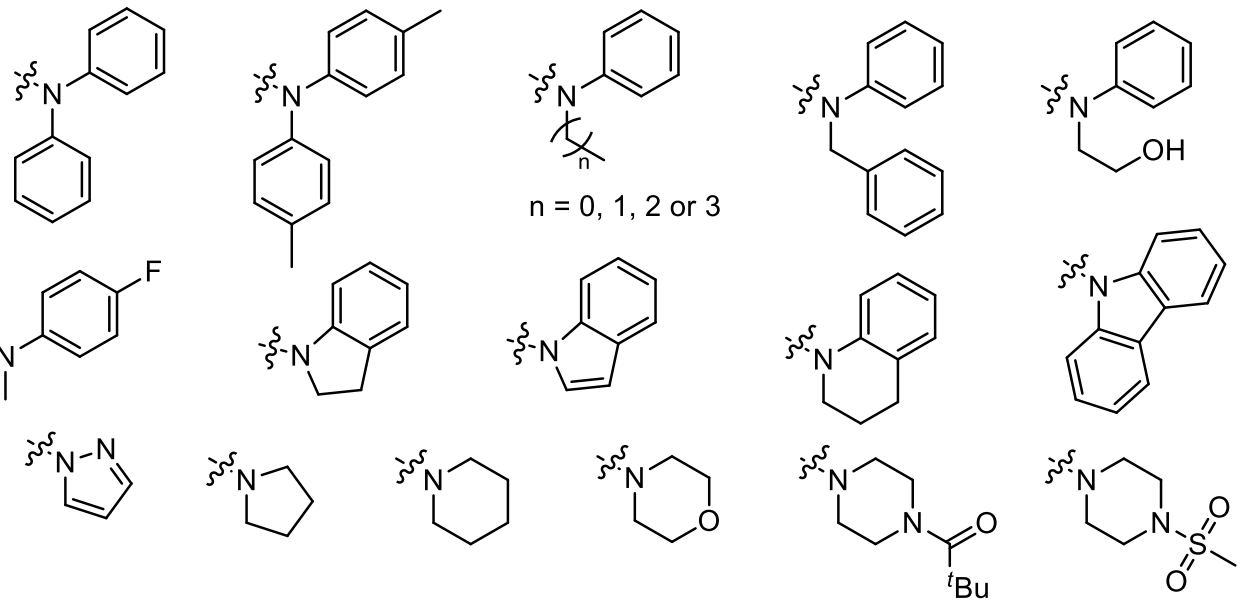

Scheme 23. A representation of tertiary amides investigated in $\mathrm{Mn}$-mediated reductive transamidation. 


\section{Reductive Amidation of Acid Chlorides and Acid Anhydrides}

Acyl chlorides as well as acid anhydrides readily react with amines under mild reaction conditions to form amides. Thus, their reactions with nitroarenes are also desirable as these offer a step-economical amide synthesis option. Most of the early reductive acylation protocols were conducted in acetic acid or acetic anhydride affording the corresponding $N$-arylacetamides. Examples of these have been reported by Baruah in 2000, where an $\mathrm{AcO}_{2}-\mathrm{Zn}-\mathrm{Al}_{2} \mathrm{O}_{3}$ system was used for acetamidation of nitroarenes at room temperature. ${ }^{69} \mathrm{In}$ 2003, Kim and co-workers reported a room-temperature indium-mediated reductive acetamidation of nitroarenes using a combination of acetic acid and acetic anhydride in methanol. ${ }^{70}$ Products were obtained in relatively short reaction times and excellent yields (Scheme 24$)$.
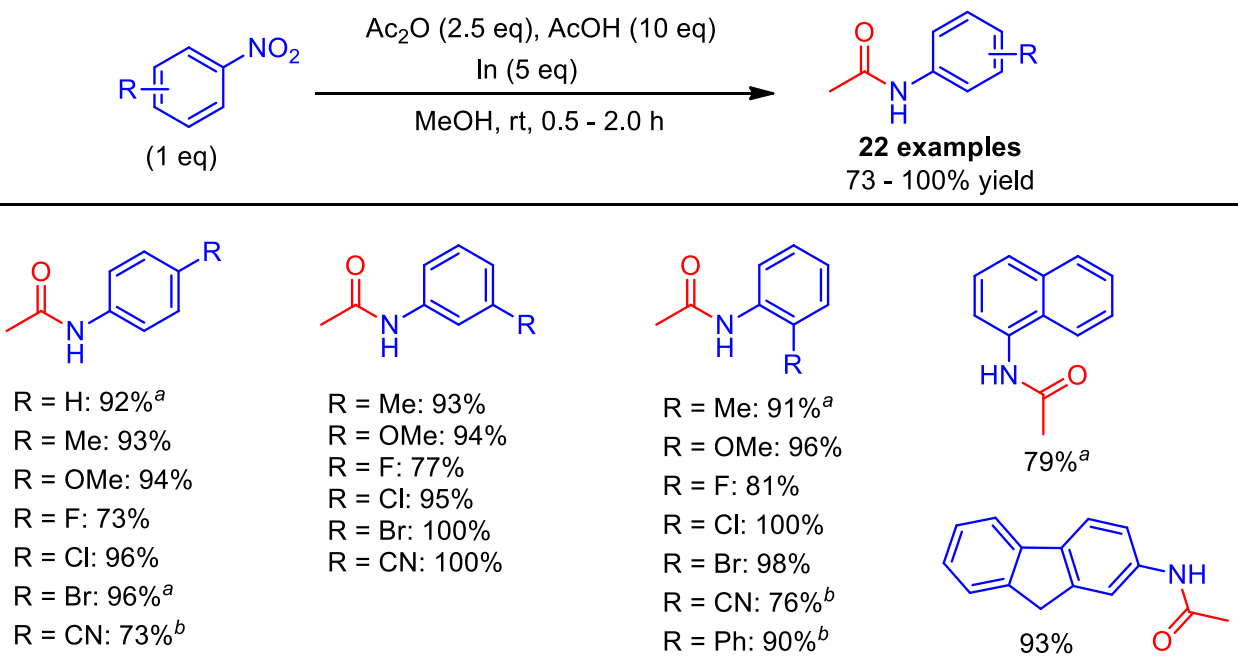

Scheme 24. Indium mediated reductive acylation of nitroarenes. ${ }^{a}$ Trace $N, O$-diacetylated product was observed. b3 $-5 \%$ of azobenzene was observed.

Furthermore, Bhattacharya and co-workers reported a thioacetate-mediated reductive acetamidation of nitroarenes to afford the desired amides in DMF or under solvent-free conditions. ${ }^{71}$ The authors then applied their protocol to synthesize an analgesic $p$-hydroxyacetamide (Acetaminophen ${ }^{\mathrm{TM}}$ ) from $p$-nitrophenol in a single step.

In 2006, Maleczka Jr and Rahaim Jr reported a Pd-catalyzed silane- or siloxane-reductive amidation, amination, sulfonamidation, carbamation and hydroxylamination of nitroarenes. ${ }^{72}$ The amidation reactions were successfully achieved in a one-pot, two-step protocol using anhydrides as carbonyl donors (Scheme 25). 4-Nitroanisole, methyl 3-nitrobenzoate and 2-nitro- $m$-xylene were reacted with different anhydrides and, in most cases, 2-nitro-m-xylene afforded the lowest product yield among the three nitroarenes. This could reasonably be probably due to increased steric effects around the nitro group of the 2-nitro-m-xylene. 


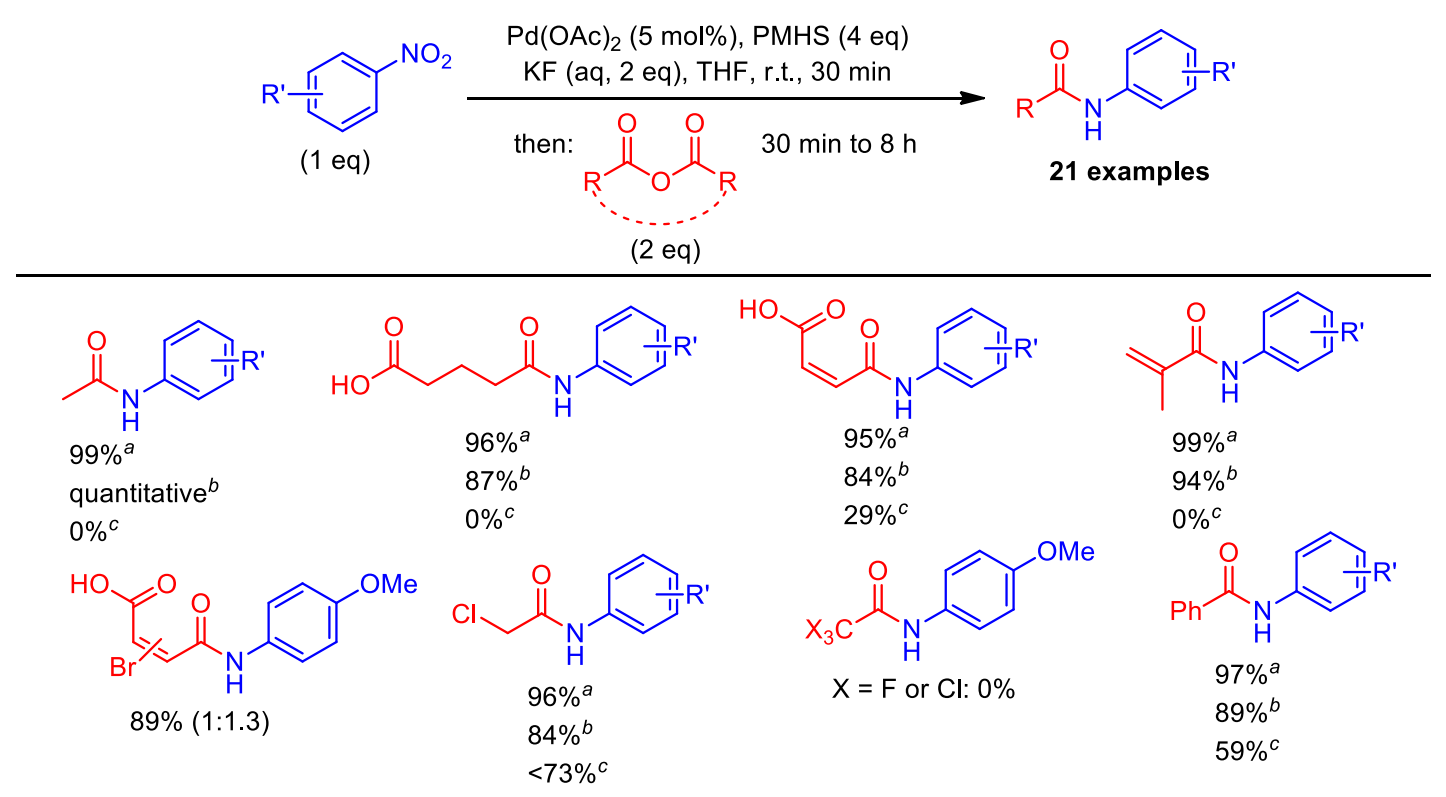

Amine source: ${ }^{a} 4-N i t r o a n i s o l e,{ }^{b}$ methyl 3-nitrobenzoate and ${ }^{c} 2$-nitro- $m$-xylene.

Scheme 25. Nitroarene reductive amidation with anhydrides.

In 2009, Hamann and co-workers reported a $\mathrm{Zn}$ and acetic acid promoted reductive amidation of nitroarenes with acyl chlorides and triethylamine (Scheme 26). ${ }^{73}$ Products were obtained in moderate yields under mild conditions and relatively short reaction times. The protocol was further used to successfully functionalize nitro derivatives of alkaloids, such as harmane as well as manzamine $A$.
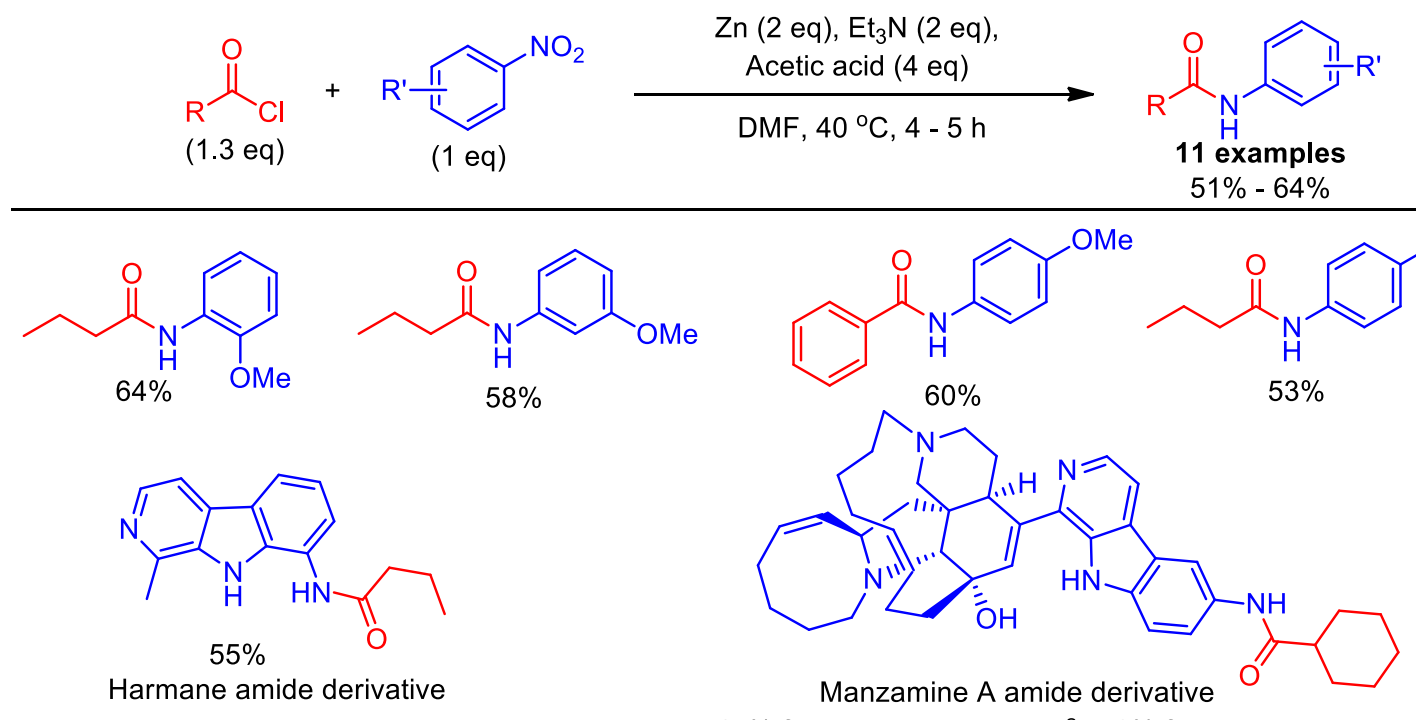

$17 \%$ from aniline derivative ${ }^{a} ; 56 \%$ from nitro derivative

${ }^{a}$ Reaction conditions: Nitroarene (1 eq), acyl chloride (1.2 eq), $\mathrm{Et}_{3} \mathrm{~N}(1.1 \mathrm{eq}), \mathrm{DMAP}$ (cat.), THF, rt, $1 \mathrm{~h}$.

Scheme 26. A representation of the products obtained by $\mathrm{Zn}$ and acetic acid promoted nitroarene acylation with acyl chlorides. 
In 2020, Benaglia and co-workers reported a metal-free, one-pot, two-step trichlorosilane-promoted reductive amidation of nitroarenes with anhydrides in the presence of methanol as an additive (Scheme 27). ${ }^{74}$ Nitroarenes with electron-withdrawing groups afforded higher product yields compared with those possessing electron-donating substituents. Reducible substituents such as nitriles and carbonyls were compatible with the protocol. Furthermore, acyl chlorides, pyridyl thioesters and lactones were also suitable acylating agents, with the latter affording functionalized amide products which could be utilized as intermediates for further synthetic manipulations.
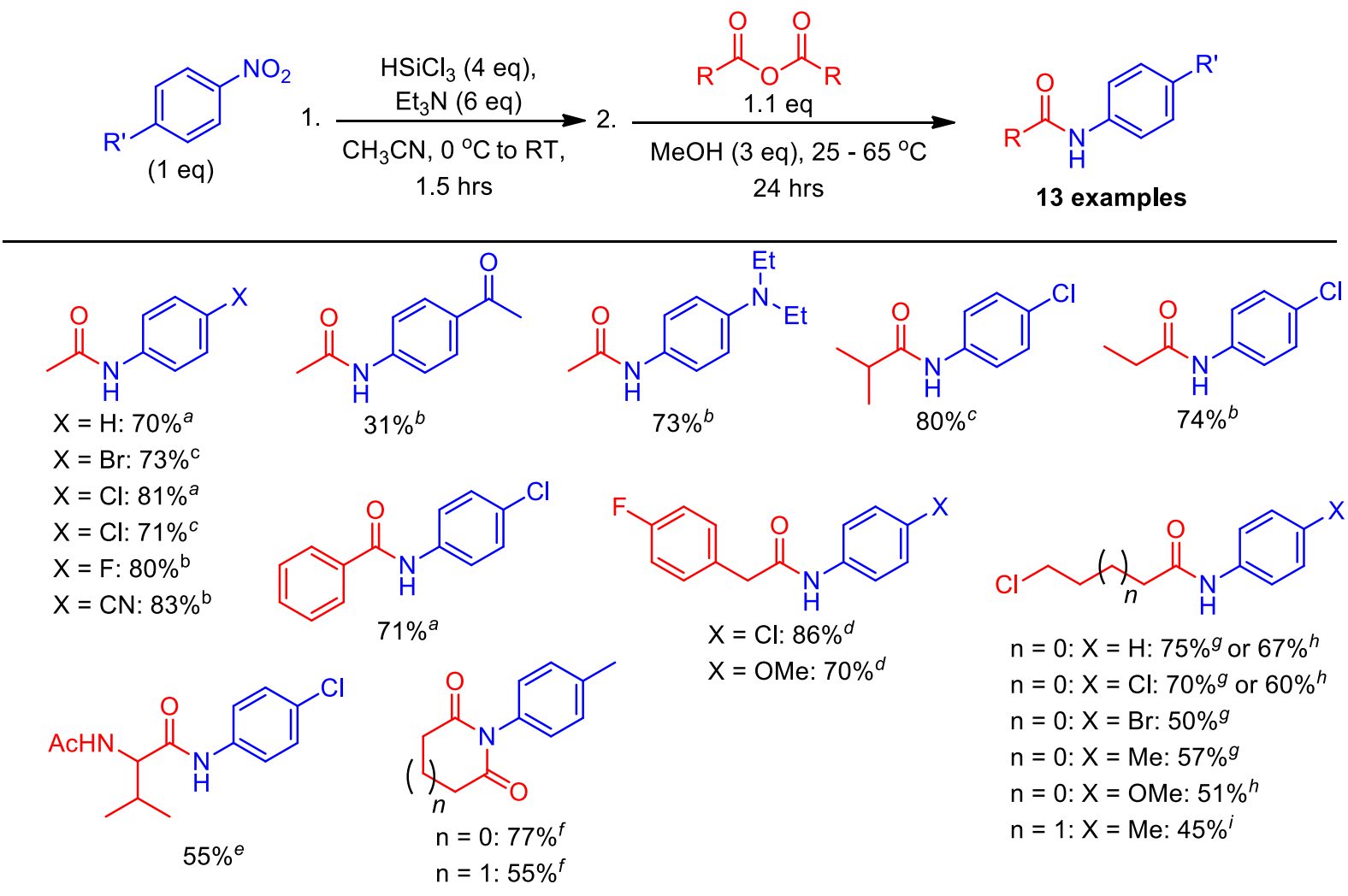

${ }^{a} \mathrm{RT} .{ }^{b}$ Reflux. ${ }^{C}$ Reflux no additive. ${ }^{d}$ Reaction conditions: $1 . \mathrm{HSiCl}_{3}(4 \mathrm{eq}), \mathrm{Et}_{3} \mathrm{~N}(6 \mathrm{eq}), \mathrm{CH}_{3} \mathrm{CN}, 0{ }^{\circ} \mathrm{C}$ to $\mathrm{RT}, 1 \mathrm{hr} ; 2$. Thioester (1.5 eq), (HF) ${ }_{3}$ TEA (3 eq), $\mathrm{CH}_{3} \mathrm{CN}$, reflux, 24 hrs. ${ }^{e}$ Reaction conditions: 1. $\mathrm{HSiCl}_{3}$ (4 eq), $\mathrm{Et}_{3} \mathrm{~N}$ (6 eq), $\mathrm{CH}_{3} \mathrm{CN}, 0^{\circ} \mathrm{C}$ to RT, $1 \mathrm{hr} ; 2$. Acyl chloride (2 eq), $\mathrm{CH}_{3} \mathrm{CN}, 24$ hrs. ${ }^{f}$ Reaction conditions: 1 . $\mathrm{HSiCl}_{3}$ (4 eq), $\mathrm{Et}_{3} \mathrm{~N}$ (6 eq), $\mathrm{CH}_{3} \mathrm{CN}, 0^{\circ} \mathrm{C}$ to RT, $1 \mathrm{hr}$; 2. Cyclic anhydride, $\mathrm{CH}_{3} \mathrm{CN}, 24$ hrs. ${ }^{g}$ Reaction conditions: $\mathrm{HSiCl}_{3}$ (4 eq), lactone (15 eq) $\mathrm{Et}_{3} \mathrm{~N}(6 \mathrm{eq}), \mathrm{CH}_{3} \mathrm{CN}, 0{ }^{\circ} \mathrm{C}$ to $82{ }^{\circ} \mathrm{C}, 24 \mathrm{hrs}$. ${ }^{h}$ Reaction conditions: $\mathrm{HSiCl}_{3}$ (4 eq), lactone (15 eq) $\mathrm{Et}_{3} \mathrm{~N}(6 \mathrm{eq}), \mathrm{CH}_{3} \mathrm{CN}, 0{ }^{\circ} \mathrm{C}$ to $95{ }^{\circ} \mathrm{C}, 24 \mathrm{hrs}$.

Scheme 27. Trichlorosilane-mediated reduction and acylation of nitroarenes and the proposed reaction mechanism.

\section{Conclusions}

Amides are found in a plethora of molecules with a broad range of beneficial applications. As a result, new methods are constantly being researched and developed to provide alternative and more sustainable ways to access amide bonds. ${ }^{29}$ Reductive amidation using nitroarenes as a direct source of nitrogen is a growing area of research and has gained momentum in recent years. This review has summarized some of the advances made 
thus far. Significant progress has been achieved in this research area with most of the reactions furnishing products from a comprehensive substrate scope. These reactions have proved to be step-economic, tolerant to different functional groups, and convenient for constructing amide bonds. Validation of the preliminary reaction mechanisms for some of the reported protocols will aid in understanding and improving the reaction conditions. Furthermore, the successful application of nitroarenes in direct reductive amidation reactions sets the stage for investigation of alkyl nitro compounds as suitable substrates for similar reactions. This creates a golden opportunity for further development and establishment of methodologies that can be applied in the synthesis of alkyl amides such as peptides.

\section{Acknowledgements}

The Center for Synthesis and Catalysis at the University of Johannesburg as well as The National Research Foundation (NRF) South Africa are acknowledged for financial support. Blessing Mkhonazi is acknowledged for helping to gather some of the articles referenced in this review.

\section{References}

1. Dawlaty, J.; Zhang, X.; Fischbach, M. A.; Clardy, J. J. Nat. Prod. 2010, 73, 441-446.

https://doi.org/10.1021/np900685z

2. Humphrey, J. M.; Chamberlin, A. R. Chem. Rev. 1997, 97, 2243-2266.

https://doi.org/10.1021/cr950005s

3. Reglero Ruiz, J. A.; Trigo-López, M.; García, F. C.; García, J. M. Polymers (Basel). 2017, 9. https://doi.org/10.3390/polym9090414

4. Winnacker, M.; Rieger, B. Polym. Chem. 2016, 7, 7039-7046.

https://doi.org/10.1039/c6py01783e

5. Zhu, L.; Chen, L. Cell. Mol. Biol. Lett. 2019, 24, 1-11.

https://doi.org/10.1186/s11658-019-0164-y

6. Ponomaryov, Y.; Krasikova, V.; Lebedev, A.; Chernyak, D.; Varacheva, L.; Chernobroviy, A. Chem.

Heterocycl. Compd. 2015, 51, 133-138.

https://doi.org/10.1007/s10593-015-1670-0

7. Volovych, I.; Neumann, M.; Schmidt, M.; Buchner, G.; Yang, J. Y.; Wölk, J.; Sottmann, T.; Strey, R.;

Schomäcker, R.; Schwarze, M. RSC Adv. 2016, 6, 58279-58287.

https://doi.org/10.1039/c6ra10484c

8. Constable, D. J. C.; Dunn, P. J.; Hayler, J. D.; Humphrey, G. R.; Leazer, J. L.; Linderman, R. J.; Lorenz, K.; Manley, J.; Pearlman, B. A.; Wells, A.; Zaks, A.; Zhang, T. Y. Green Chem. 2007, 9, 411-442.

https://doi.org/10.1039/b703488c

9. Bryan, M. C.; Dunn, P. J.; Entwistle, D.; Gallou, F.; Koenig, S. G.; Hayler, J. D.; Hickey, M. R.; Hughes, S.; Kopach, M. E.; Moine, G.; Richardson, P.; Roschangar, F.; Steven, A.; Weiberth, F. J. Green Chem. 2018, 20, 5082-5103.

https://doi.org/10.1039/c8gc01276h

10. Dunetz, J. R.; Magano, J.; Weisenburger, G. A. Org. Process Res. Dev. 2016, 20, 140-177.

https://doi.org/10.1021/op500305s

11. Mcknelly, K. J.; Sokol, W.; Nowick, J. S. 2020.

https://doi.org/10.1021/acs.joc.9b03280 
12. Tam, E. K. W.; Rita; Liu, L. Y.; Chen, A. European J. Org. Chem. 2015, 2015, 1100-1107. https://doi.org/10.1002/ejoc.201403468

13. Lanigan, R. M.; Starkov, P.; Sheppard, T. D. J. Org. Chem. 2013, 78, 4512-4523.

https://doi.org//10.1021/jo400509n

14. Leggio, A.; Bagalà, J.; Belsito, E. L.; Comandè, A.; Greco, M.; Liguori, A. Chem. Cent. J. 2017, 11, 1-12. https://doi.org/10.1186/s13065-017-0318-9

15. Lundberg, H.; Tinnis, F.; Adolfsson, H. Appl. Organomet. Chem. 2019, 33, 1-5.

https://doi.org/10.1002/aoc.5062

16. Lundberg, H.; Adolfsson, H. ACS Catal. 2015, 5, 3271-3277.

https://doi.org/10.1021/acscatal.5b00385.

17. Ben Halima, T.; Masson-Makdissi, J.; Newman, S. G. Angew. Chemie - Int. Ed. 2018, 57, 12925-12929. https://doi.org/10.1002/anie.201808560

18. Li, G.; Szostak, M. Nat. Commun. 2018, 9, 1-8. https://doi.org/10.1038/s41467-018-06623-1

19. Ghosh, S. C.; Ngiam, J. S. Y.; Seayad, A. M.; Tuan, D. T.; Chai, C. L. L.; Chen, A. J. Org. Chem. 2012, 77, 8007-8015.

https://doi.org/10.1021/j0301252c

20. Jamalifard, S.; Mokhtari, J.; Mirjafary, Z. RSC Adv. 2019, 9, 22749-22754.

https://doi.org/10.1039/c9ra04216d

21. Chandra, S.; Hyeok, S. European J. Org. Chem. 2010, 2010, 4266-4270.

https://doi.org/10.1002/ejoc.201000362

22. Wang, G.; Shen, Y.; Wu, X. Eur. J. Med. Chem. 2008, No. Entry 3, 4367-4371.

https://doi.org/10.1002/ejoc.200800413

23. Wu, X.; Hu, L. J. Org. Chem. 2007, 72, 765-774.

https://doi.org/10.1021/jo061703n

24. Lundberg, H.; Tinnis, F.; Selander, N.; Adolfsson, H. Chem. Soc. Rev. 2014, 43, 2714-2742. https://doi.org/10.1039/c3cs60345h

25. Joullié, M. M.; Lassen, K. M. Arkivoc 2010, 2010, 189-250.

https://doi.org/10.3998/ark.5550190.0011.816

26. De Figueiredo, R. M.; Suppo, J. S.; Campagne, J. M. Chem. Rev. 2016, 116, 12029-12122.

https://doi.org/10.1021/acs.chemrev.6b00237

27. Shaikh, N. S. ChemistrySelect 2019, 4, 6753-6777.

https://doi.org/10.1002/slct.201900460

28. Pattabiraman, V. R.; Bode, J. W. Nature 2011, 480, 471-479.

https://doi.org/10.1038/nature10702

29. Santos, A. S.; Silva, A. M. S.; Marques, M. M. B. European J. Org. Chem. 2020, 2020, 2501-2516.

https://doi.org/10.1002/ejoc.202000106

30. Montalbetti, C. A. G. N.; Falque, V. Tetrahedron 2005, 61, 10827-10852.

https://doi.org/10.1016/j.tet.2005.08.031

31. Lanigan, R. M.; Sheppard, T. D. European J. Org. Chem. 2013, No. 33, 7453-7465.

https://doi.org/10.1002/ejoc.201300573

32. Massolo, E.; Pirola, M.; Benaglia, M. European J. Org. Chem. 2020.

https://doi.org/10.1002/ejoc.202000080

33. Albericio, F. Curr. Opin. Chem. Biol. 2004, 8, 211-221. 
https://doi.org/10.1016/j.cbpa.2004.03.002

34. Ono, N. In The Nitro Group In Organic Synthesis; Feuer, H., Ed.; Wiley-VCH, 2001; pp 159-181.

35. Ragaini, F. J. Chem. Soc. Dalt. Trans. 2009, No. 32, 6251-6266.

https://doi.org/10.1039/b902425p

36. Wienhöfer, G.; Sorribes, I.; Boddien, A.; Westerhaus, F.; Junge, K.; Junge, H.; Llusar, R.; Beller, M. J. Am. Chem. Soc. 2011, 133, 12875-12879.

https://doi.org/10.1021/ja2061038

37. Shokri, Z.; Zeynizadeh, B.; Hosseini, S. A. J. Colloid Interface Sci. 2017, 485, 99-105.

https://doi.org/10.1016/i.jcis.2016.09.019

38. Zeynizadeh, B.; Rahmani, S.; Tizhoush, H. Polyhedron 2020, 175, 114201.

https://doi.org/10.1016/i.poly.2019.114201

39. Zeynizadeh, B.; Shokri, Z.; Hasanpour Galehban, M. Appl. Organomet. Chem. 2019, 33, 1-11. https://doi.org/10.1002/aoc.4771

40. Owsley, D. C.; Bloomberg, J. J. Synthesis (Stuttg). 1977, 1977, 118-120.

https://doi.org/10.1055/s-1977-24290

41. Ho, T. L. J. Org. Chem. 1977, 42, 3755.

https://doi.org/10.1021/jo00443a028

42. Watanabe, Y.; Tsuji, Y.; Hondo, T.; Takeuchi, R. J. Org. Chem. 1984, 49, 4451-4455.

https://doi.org/10.1021/jo00197a023

43. Lee, K.-Y.; Kim, J.-M.; Kim, J.-N. Bull. Korean Chem. Soc. 2002, 23, 1359-1360.

https://doi.org/10.5012/bkcs.2002.23.10.1359

44. Kumar, V.; Kumar, M.; Sharma, S.; Kumar, N. RSC Adv. 2014, 4, 11826-11830.

https://doi.org/10.1039/c3ra46619a

45. Du, X.; Zheng, M.; Chen, S.; Xu, Z. Synlett 2006, No. 12, 1953-1955.

https://doi.org/10.1055/s-2006-947334

46. Kumar, A.; Akula, H. K.; Lakshman, M. K. European J. Org. Chem. 2010, No. 14, 2709-2715.

https://doi.org/10.1002/ejoc.200901420

47. Wang, S. P.; Cheung, C. W.; Ma, J. A. J. Org. Chem. 2019, 84, 13922-13934.

https://doi.org/10.1021/acs.joc.9b02068

48. Morimoto, H.; Fujiwara, R.; Shimizu, Y.; Morisaki, K.; Ohshima, T. Org. Lett. 2014, 16, 2018-2021.

https://doi.org/10.1021/ol500593v

49. Mkhonazi, B. D.; Shandu, M.; Tshinavhe, R.; Simelane, S. B.; Moshapo, P. T. Molecules 2020, 25, 1-9.

https://doi.org/10.3390/molecules25051040

50. Wang, X.; Guo, H.; Xie, G.; Zhang, Y. Synth. Commun. 2004, 34, 3001-3008.

https://doi.org/10.1081/SCC-200026659

51. Cheung, C. W.; Ploeger, M. L.; Hu, X. Nat. Commun. 2017, 8, 1-10.

https://doi.org/10.1038/ncomms14878

52. Ploeger, M. L.; Darù, A.; Harvey, J. N.; Hu, X. ACS Catal. 2020, 10, 2845-2854.

https://doi.org/10.1021/acscatal.9b05049

53. Cheung, C. W.; Shen, N.; Wang, S. P.; Ullah, A.; Hu, X.; Ma, J. A. Org. Chem. Front. 2019, 6, 756-761. https://doi.org/10.1039/c8q001405a

54. Ling, L.; Chen, C.; Luo, M.; Zeng, X. Org. Lett. 2019, 21, 1912-1916.

https://doi.org/10.1021/acs.orglett.9b00554

55. Fang, X.; Jackstell, R.; Beller, M. Angew. Chemie - Int. Ed. 2013, 52, 14089-14093. 
https://doi.org/10.1002/anie.201308455

56. Zhou, F.; Wang, D. S.; Guan, X.; Driver, T. G. Angew. Chemie - Int. Ed. 2017, 56, 4530-4534.

https://doi.org/10.1002/anie.201612324

57. Cheung, C. W.; Leendert Ploeger, M.; Hu, X. Chem. Sci. 2018, 9, 655-659.

https://doi.org/10.1039/c7sc03950f

58. Peng, J. B.; Geng, H. Q.; Li, D.; Qi, X.; Ying, J.; Wu, X. F. Org. Lett. 2018, 20, 4988-4993.

https://doi.org/10.1021/acs.orglett.8b02109

59. Peng, J.; Geng, H.; Wu, X. 2019.

https://doi.org/10.1021/acs.orglett.9b01772

60. Shen, N.; Cheung, C. W.; Ma, J. A. Chem. Commun. 2019, 55, 13709-13712.

https://doi.org/10.1039/c9cc06638a

61. Zhao, S.; Mankad, N. P. Org. Lett. 2019, 21, 10106-10110.

https://doi.org/10.1021/acs.orglett.9b04092

62. Jain, S. K.; Aravinda Kumar, K. A.; Bharate, S. B.; Vishwakarma, R. A. Org. Biomol. Chem. 2014, 12, 64656469.

https://doi.org/10.1039/c4ob01155d

63. Maltha, A.; Favre, T. L. F.; Kist, H. F.; Zuur, A. P.; Ponec, V. Journal of Catalysis. 1994, pp 364-374.

https://doi.org/10.1006/jcat.1994.1304

64. Sheng, G.; Wu, X.; Cai, X.; Zhang, W. Synth. 2015, 47, 949-954.

https://doi.org/10.1055/s-0034-1380111

65. Nordstrøm, L. U.; Vogt, H.; Madsen, R. J. Am. Chem. Soc. 2008, 130, 17672-17673.

https://doi.org/10.1021/ja808129p

66. Xiao, F.; Liu, Y.; Tang, C.; Deng, G. J. Org. Lett. 2012, 14, 984-987.

https://doi.org/10.1021/ol203211k

67. Cheung, C. W.; Ploeger, M. L.; Hu, X. ACS Catal. 2017, 7, 7092-7096.

https://doi.org/10.1021/acscatal.7b02859

68. Cheung, C. W.; Ma, J. A.; Hu, X. J. Am. Chem. Soc. 2018, 140, 6789-6792.

https://doi.org/10.1021/jacs.8b03739

69. Baruah, R. N. Indian J. Chem. - Sect. B Org. Med. Chem. 2000, 39, 300-303.

70. Kim, B. H.; Han, R.; Piao, F.; Jun, Y. M.; Baik, W.; Lee, B. M. Tetrahedron Lett. 2003, 44, 77-79. https://doi.org/10.1016/S0040-4039(02)02479-6

71. Bhattacharya, A.; Purohit, V. C.; Suarez, V.; Tichkule, R.; Parmer, G.; Rinaldi, F. Tetrahedron Lett. 2006, 47, 1861-1864.

https://doi.org/10.1016/j.tetlet.2005.09.196

72. Rahaim, R. J.; Maleczka, R. E. Synthesis (Stuttg). 2006, No. 19, 3316-3340.

https://doi.org/10.1055/s-2006-950231

73. Wahba, A. E.; Peng, J.; Hamann, M. T. Tetrahedron Lett. 2009, 50, 3901-3904.

https://doi.org/10.1016/j.tetlet.2009.04.061

74. Massolo, E.; Pirola, M.; Puglisi, A.; Rossi, S.; Benaglia, M. RSC Adv. 2020, 10, 4040-4044.

https://doi.org/10.1039/c9ra10758d 


\section{Authors' Biographies}

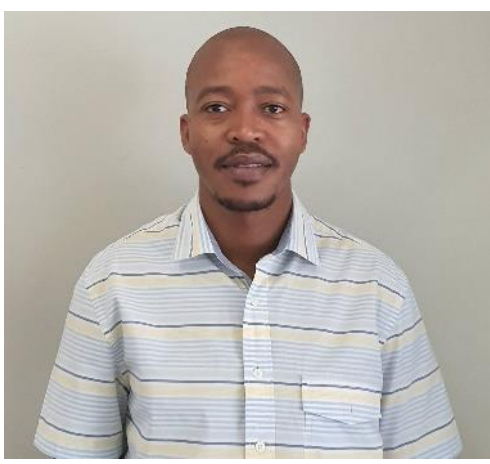

Paseka Thendo Moshapo was born in Venda, Limpopo province. He obtained his MSc degree in 2013 and PhD in 2017 from the University of Johannesburg, South Africa. He was appointed as an assistant lecturer at the same institution during his final year of PhD research. He was then appointed as an organic chemistry lecturer in the Faculty of Science at the University of Johannesburg in 2017. His research interests are methodology development for the synthesis of bioactive molecules, carbohydrate chemistry and catalysis.

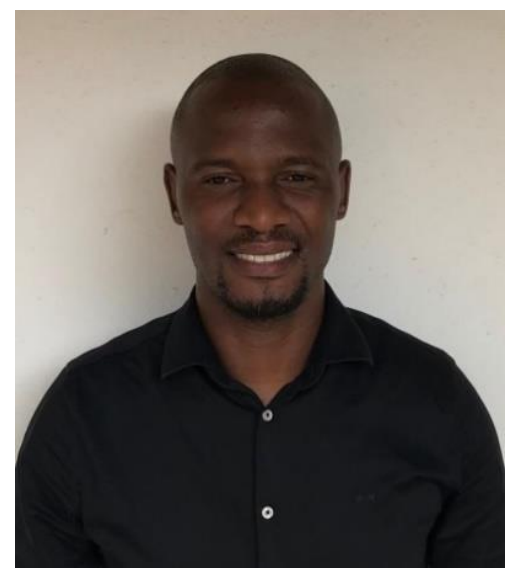

Sandile Bongani Simelane is a lecturer of organic chemistry in the Faculty of Science and Engineering at the University of Eswatini (Kwaluseni, Eswatini). He obtained a Master's Degree in Chemistry (2011) from the University of Johannesburg. He received his PhD in Chemistry (2015) from the University of Johannesburg (UJ) which was subsequently followed by a 2-year postdoctoral stint at the Drug Discovery \& Development Centre (H3D) in University of Cape Town (UCT). His research interests include carbohydrate chemistry and synthesis of bioactive heterocyclic compounds. 